\title{
Associations Between Behavioral Effects of Bisphenol A and DNA Methylation in Zebrafish Embryos
}

\author{
Pål A. Olsvik ${ }^{1 * t}$, Paul Whatmore ${ }^{1}$, Sam J. Penglase ${ }^{1 \dagger}$, Kaja H. Skjærven ${ }^{1}$, \\ Marc Anglès d'Auriac ${ }^{2}$ and Ståle Ellingsen ${ }^{1 \dagger}$ \\ ${ }^{1}$ Institute of Marine Research, Bergen, Norway, ${ }^{2}$ Norwegian Institute for Water Research, Oslo, Norway
}

OPEN ACCESS

Edited by:

Eric Blomme,

AbbVie, United States

Reviewed by:

Kevin Gerrish,

National Institute of Environmental Health Sciences (NIEHS),

United States

Xuefang Liang,

Inner Mongolia University, China

*Correspondence:

Pål A. Olsvik

pal.a.olsvik@nord.no

${ }^{\dagger}$ Present address:

Pål A. Olsvik,

Nord University, Bodø, Norway

Sam J. Penglase,

School of Marine and Tropical Biology, James Cook University, Townsville,

QLD, Australia

Ståle Ellingsen,

University of Bergen, Bergen, Norway

Specialty section:

This article was submitted to

Toxicogenomics,

a section of the journal

Frontiers in Genetics

Received: 23 November 2018

Accepted: 19 February 2019

Published: 08 March 2019

Citation:

Olsvik PA, Whatmore $P$,

Penglase SJ, Skjærven KH,

Anglès d'Auriac $M$ and Ellingsen $S$

(2019) Associations Between

Behavioral Effects of Bisphenol

A and DNA Methylation in Zebrafish

Embryos. Front. Genet. 10:184.

doi: 10.3389/fgene.2019.00184
Endocrine-disrupting contaminants have been associated with aberrant changes in epigenetic pathways in animals. In this study, zebrafish embryos were exposed bisphenol A (BPA) to search for associations between behavior and epigenetic mechanisms in fish. For concentration-dependent responses, embryos were exposed to a range of BPA concentrations $(0.1 \mathrm{nM}$ to $30 \mu \mathrm{M})$. Embryos were analyzed for locomotor activity at 3-, 4-, and 5-days post fertilization (dpf) in response to changing light conditions. Based on concentration-dependent effects on behavior and gene expression, $10 \mu \mathrm{M}$ BPA [from 24 to 96 hours post fertilization (hpf)] was used for a whole-genome bisulfite sequencing (WGBS) study searching for genome-wide impacts on DNA methylation. Over the examined concentration ranges, hyperactivity was demonstrated for exposures to $0.001 \mu \mathrm{M}$ BPA in comparison to embryos exposed to lower or higher BPA concentrations. Transcriptional analysis showed significant effects at $>0.01 \mu \mathrm{M}$ BPA for two genes related to DNA methylation (dnmt1, cbs). BPA exposure did not significantly affect global DNA methylation, but 20,474 differentially methylated (DM) sites in 4,873 genes were identified by WGBS analysis. Most DM sites were identified within gene bodies. The genes with the most DM sites were all protocadherin 2 gamma subfamily genes, related to axon targeting, synaptic development and neuronal survival. KEGG pathways most significantly affected by BPA exposure were phosphatidylinositol signaling system, followed by VEGF and MAPK signaling pathways. This study shows that BPA can affect zebrafish embryo swimming activity at very low concentrations as well as affecting numerous methylated sites in genes which are overrepresented in functionally relevant metabolic pathways. In conclusion, altered methylation patterns of genes associated with nervous system development might lead to abnormal swimming activity.

Keywords: zebrafish embryos, bisphenol A, behavior, gene expression, DNA methylation, epigenetics

\section{INTRODUCTION}

As part of an ongoing effort to study the mechanistic effects of endocrine-disrupting contaminants found in Atlantic salmon (Salmo salar) feeds, we are using zebrafish (Danio rerio) embryos and bisphenol A (BPA) as a model to study behavioral and molecular endpoints of chemical exposure in farmed fish. Aquaculture feeds may contain significant concentrations of contaminants 
such as dioxins (PCDD/PCDF), $\mathrm{PCB}$ and $\mathrm{PBDE}$, and pesticides such as DDE and chlorpyrifos (Berntssen et al., 2010, 2011; Nacher-Mestre et al., 2014). Most of these contaminants will bioaccumulate in fish.

Many studies have described associations between endocrine-disrupting contaminants and the epigenome in fish (Iida et al., 2006; Aniagu et al., 2008; Mirbahai et al., 2011; Olsvik et al., 2014). BPA, one of the most ubiquitous plasticizing compounds and best-studied endocrine disruptors (Cole et al., 2011; Rubin, 2011; Rochester, 2013), has been associated with altered DNA methylation in mammalian cells (Walker and Gore, 2011). In fish, BPA, acting on DNA methylation, affects numerous mechanisms; immune system (Lam et al., 2011), reproductive function (Laing et al., 2016; Chen et al., 2017), antioxidant enzyme activity (Wu et al., 2011), detoxification (Lindholst et al., 2003; Bonefeld-Jorgensen et al., 2007; Olsvik et al., 2009; Maradonna et al., 2014; Bugel et al., 2016), and larval and adult behavior (Saili et al., 2012, 2013; Wang et al., 2013; Little and Seebacher, 2015; Li et al., 2017). Hyperactivity has been reported in zebrafish larvae exposed to $\geq 10 \mathrm{nM}$ BPA (Saili et al., 2012). Significantly decreased swimming speed in response to alternating light stimulation has been observed in 120 hpf zebrafish larvae exposed to 1-15 $\mu \mathrm{M}$ BPA from 6 to 96 hpf (Wang et al., 2013).

In developing zebrafish, it has been shown that transient exposure to BPA results in hyperactivity (Saili et al., 2012), a response associated with altered gene expression (Saili et al., 2013). At $0.1 \mu \mathrm{M}$ BPA exposure, suppressed expression of genes involved in nervous system development and function has been associated with altered behavioral responses (hyperactivity) to light stimuli in zebrafish embryos (Saili et al., 2013). Reduced expression of DNA methyltransferase 1 (dnmt1), as well as reduced levels of global DNA methylation, has been observed in tissues of zebrafish exposed to environmentally relevant concentrations of BPA (Laing et al., 2016). Although BPA is known to impact behavior, gene expression and DNA methylation in developing zebrafish larvae, more knowledge is needed on concentration-dependent responses and genome-wide DNA methylation to better understand the epigenetic impact of such chemicals. Conservation of DNA methylation patterns has been observed between various animals (Feng et al., 2010) and we postulate that the underlying molecular mechanisms imposed by BPA and other endocrine-disrupting chemicals will offer sufficient overlap to make comparative studies valuable.

The aim of this study was to attempt to link behavioral responses to changes in global DNA methylation in fish exposed to BPA, selected as a model endocrine-disrupting chemical. In order to determine the lowest BPA concentration affecting behavioral endpoints, zebrafish embryos were exposed to BPA concentrations between $0.1 \mathrm{nM}$ and $30 \mu \mathrm{M}(22 \mathrm{ng} / \mathrm{L}-6.8 \mathrm{mg} / \mathrm{L})$ for $24 \mathrm{~h}$ during a critical period of embryonic development (2-26 hpf). A set of transcriptional markers were also quantified to assess concentration-dependent effects of BPA in the embryos. To improve the chances of finding significant DNA methylation effects we selected a dose of $10 \mu \mathrm{M}$ for the 72-h exposure experiment. This dose was selected based on the Saili et al. $(2012,2013)$ studies and our own preliminary study that all showed no lethality below $30 \mu \mathrm{M}$ BPA, and locomotor analyses which showed linear significant responses to BPA exposure at concentrations between 1 and $30 \mu \mathrm{M}$ BPA. This treatment $(10$ $\mu \mathrm{M}$ BPA) was used to identify methylated genomic regions with whole-genome bisulfite sequencing (WGBS) through later stages of embryonic development (24-96 hpf), and to elucidate possible links between behavioral, transcriptional and methylation endpoints. Other studies have examined DNA methylation in zebrafish as a response to BPA exposure, but they examined only a handful of promoters and used generalized quantification methods such as luminometric-based assay (LUMA) to assess global DNA methylation. WGBS allows a much more comprehensive analysis by examining individual methylated (and, importantly, unmethylated) cytosines across the entire genome. To our knowledge, this is the first study to use WGBS in search of BPA-induced effects on genome-wide DNA methylation in zebrafish embryos.

\section{MATERIALS AND METHODS}

\section{Embryo Exposure to BPA}

Fish were maintained and experiments conducted in compliance with the Norwegian Animal Welfare Act guidelines. Zebrafish embryos for the exposure experiments were obtained from wild type brood stock ( $\mathrm{AB}$ \% and TL $0^{7}$ strains). These adult fish were maintained under standard conditions $\left(28.5^{\circ} \mathrm{C}, 500 \mu \mathrm{S} \mathrm{EC}\right.$, $\mathrm{pH}$ 7.6, 10\% daily water exchange, 14:10 light:dark photoperiod) in a closed recirculation system (Aquatic habitats, Apopka, FL, United States). The adults were fed twice daily to satiation with a mixture of first instar Artemia nauplii (Sanders, South Ogden, UT, United States) and Gemma Micro 500 (Skretting c/o Trouw France S.A., Vervins, France). Prior to mating, adult fish were removed from the recirculation system and separated by sex within the $9 \mathrm{~L}$ spawning tanks (Techniplast, Buguggiate, Italy) in system water at sex ratios averaging $10^{r}: 2 \%$, in the afternoon prior to mating. On the morning of the next day, the two sexes were combined in a spawning tank containing fresh system water, which was placed on $\mathrm{a} \approx 20^{\circ}$ degree lengthwise slope to enhance mating success. The fish were then allowed to interact for a 1-1.5 $\mathrm{h}$ period before spawned eggs were collected.

Spawned eggs were pooled, rinsed with and then placed into E3 embryo medium and sorted into $\approx 70$ eggs/well in six well plates (Nunclon Delta Surface, Thermo Scientific, Roskilde, Denmark). Our aim was to expose embryos to sublethal graded concentrations of BPA ( $\geq 99 \%$ purity, Sigma-Aldrich, MO, United States) from 2 to $26 \mathrm{hpf}$ ( $24 \mathrm{~h}$ exposure during critical development period) for behavioral and transcriptional analysis, and from 24 to $96 \mathrm{hpf}$ (72 $\mathrm{h}$ exposure) for methylation analysis. BPA was dissolved in dimethyl sulfoxide (DMSO, $>99.9 \%$ purity, Sigma-Aldrich) to make a stock solution $(100 \mu \mathrm{M}$ BPA in DMSO). Between 2 and $2.5 \mathrm{hpf}$, excess E3 embryo medium was removed from the center bottom of each well, allowing eggs to gather in the depression present at the edge. Four milliliters of treatment medium was then added to each well (three wells per treatment). Treatments were E3 media with $0.1 \% \mathrm{DMSO}$ and one level of $0,0.0001,0.001,0.01,0.1,1,10,30 \mu \mathrm{M}$ of BPA. Embryos 
used to identify methylated genomic regions were only exposed to $10 \mu \mathrm{M}$ BPA. Higher levels were not used as they result in high levels of embryo deformity (90 $\mu \mathrm{M}$ BPA; $100 \%$ deformity at 24 hpf, personal observation). In addition, there was a control (E3 media) without DMSO or BPA.

Eggs were then maintained in an incubator at $28.5^{\circ} \mathrm{C}$ with a light:dark cycle of 16:8 h for the trial period. We exposed embryos from 2 to $26 \mathrm{hpf}$. At $4-6 \mathrm{hpf}, \approx 50$ embryos from each well were transferred to a new 6 -well plate, the excess media removed from the well as before, and the treatment continued by adding another $4 \mathrm{ml}$ of the respective treatment solutions. At $26 \mathrm{hpf}(24 \mathrm{~h}$ of exposure), treatment solutions were removed from wells and rinsed twice for 5 min using E3 media. Each replicate of embryos was then transferred to the well of a 6-well plate, the remaining media removed and replaced with $\mathrm{E} 3(\approx 8 \mathrm{ml})$. Thereafter, E3 media was replaced $(\approx 80 \%$ exchange) daily.

\section{Embryo Analysis - Survival, Hatch, and Deformities}

Embryo mortality was measured at 24, 48 (one otolith length migration away from the eye), 72, 96, and $120 \mathrm{hpf}$, and deformities were evaluated at 24, 48, and $72 \mathrm{hpf}$. Deformities were evaluated by scanning embryos at $10 \times$ magnification, with further evaluation of those embryos found to be deformed at $20 \times$ magnification, using a stereomicroscope. Hatching percentage was calculated at $48,54,72$, and $96 \mathrm{hpf}$.

\section{Larval Locomotor Activity}

At 72 hpf, eight embryos showing no signs of deformities from each treatment replicate (24 embryos/treatment) were used for locomotor analysis. Larvae were transferred to individual wells of a 96-well plate in a randomized design, and analyzed for locomotor activity at 3,4 , and $5 \mathrm{dpf}$ in response to changing light conditions, using an automated video tracking system (Zebralab, Viewpoint, Lyon, France) in a similar manner as previously described (Penglase et al., 2014). Several methods of locomotor analysis were conducted in this trial, both to assess the effects of BPA on larval locomotor activity, and as part of a larger project to refine methods for effectively analyzing larval locomotor activity.

Locomotor analysis variant 1: The method for this variant was similar to that previously described (Burgess and Granato, 2007). Modifications to this method were the threshold levels for locomotor activity (Low:Medium:High activity, 7:15:50), the length of analysis ( 5 min light followed by 5 or 10 min dark, data binned into $5 \mathrm{~min}$ lots). With these settings, low activity was where no movement occurred, so data were further grouped into either no (low) or active (medium + high) locomotor activity for statistical analyses. The same plate was used on each day, and maintained in the incubator when not being analyzed for locomotor activity. A total of eight larvae were utilized per replicate, except for the DMSO control (16 larvae) and the E3 control (24 larvae). Larvae were analyzed with this method at 3, 4, and 5 dpf. Locomotor analysis variant 2: This method was similar to variant one, but aimed to determine the effects of BPA on the response to dark "flashes" (short periods of darkness). The response of zebrafish larvae to dark flashes is described by Burgess and Granato (2007). Differences from variant one were the length of analysis ( $1 \mathrm{~s}$ dark followed by $9 \mathrm{~s}$ light $\times 3$, total analysis length $30 \mathrm{~s}$ ), binning (5 s) and larval age (this method was only utilized at $4 \mathrm{dpf}$ ). Locomotor analysis variant 3: This method was similar to variant two, with differences being length of analysis ( $0.5 \mathrm{~s}$ dark followed by $2.5 \mathrm{~s}$ light $\times 3$, total analysis length $9 \mathrm{~s}$ ), binning (1 s) and larval age (this method utilized at 4 and $5 \mathrm{dpf}$ ). Locomotor analysis variant 4: This method aimed to analysis larval locomotor activity under less confined conditions. In this method, two larvae from each replicate (six per treatment) were placed into individual wells of 12 well plates and wells were adjusted to $\approx 1 \mathrm{ml}$ of E3. Larval locomotor activity was then analyzed in the viewpoint system with the tracking mode $(5 \mathrm{~min}$ light followed by 5 min dark, data binned into $5 \mathrm{~min}$ lots). In addition to variants $1-3$, this method enabled the analysis of the distances moved by the larvae when moving slowly (between 1 and $3 \mathrm{~mm} / \mathrm{s}$ ) or quickly $(>3 \mathrm{~mm} / \mathrm{s})$. Other settings within the viewpoint system utilized for this analysis were "transparent" larvae, and sensitivity of 108. Due to the limited number of wells on a 12-well plate, only the DMSO control and 1, 10, and $30 \mu \mathrm{M}$ exposure groups were analyzed with this method. Larvae were analyzed with this method at $5 \mathrm{dpf}$.

\section{Sampling}

At $5 \mathrm{dpf}$, embryos from the locomotor activity trial were pooled with the remaining embryos from that replicate and the embryos euthanized $(\approx 0.4 \mathrm{~g} / \mathrm{L}$ MS222 neutralized with $0.4 \mathrm{~g} / \mathrm{L} \mathrm{NaHCO}_{3}$ ). The embryos (30-50 depending on treatment) were then transferred to Eppendorf tubes, the remaining E3 solution removed (100 $\mu \mathrm{L}$ remaining), and $0.3 \mathrm{~mL}$ of Trizol reagent (Invitrogen, Life Technologies, Carlsbad, CA, United States) was added. Samples were incubated at room temperature for $5 \mathrm{~min}$, and homogenized by hand shaking for $1 \mathrm{~min}$ and then frozen and stored at $-80^{\circ} \mathrm{C}$ until analysis.

\section{RNA Isolation and RT-qPCR}

Zebrafish embryos (pools of 40 per sample) were homogenized using ceramic beads CK28 and a Precellys 24 homogenizer (Bertin Technologies, Montigny-le-Bretonneux, France). Total RNA was extracted using RNA Tissue Mini Kit (Qiagen, Hilden, Germany) and the BioRobot EZ1, treated with DNase according to the manufacturer's instructions and eluted in $50 \mu \mathrm{L}$ RNase-free MilliQ $\mathrm{H}_{2} \mathrm{O}$. Quality and integrity of extracted RNA were validated with the NanoDrop ND-1000 Spectrophotometer (NanoDrop Technologies, Wilmington, DE, United States) and the Agilent 2100 Bioanalyzer (Agilent Technologies, Palo Alto, CA, United States).

PCR primer sequences used for quantification of the transcriptional levels of the evaluated genes are shown in Table $\mathbf{1 .}$ A two-step real-time RT-PCR protocol previously described by Olsvik et al. (2014) was used to quantify the transcriptional levels of the selected genes. Mean normalized expression (MNE) of the target genes was determined using a normalization factor based upon $a c t b$, eef1a1, and uba52 $(M<0.59)$, as calculated by the geNorm software (Vandesompele et al., 2002). 
TABLE 1 | PCR primers, accession numbers, amplicon sizes, and PCR efficiencies.

\begin{tabular}{|c|c|c|c|c|c|c|c|}
\hline Gene symbol & Gene name & Potential marker for & Accession no. & Forward primer & Reverse primer & $\begin{array}{l}\text { Amplicon } \\
\text { size (bp) }\end{array}$ & $\begin{array}{c}\text { PCR } \\
\text { efficiency }\end{array}$ \\
\hline$d n m t 1$ & DNA (cytosine-5-)-methyltransferase 1 & DNA methylation & NM_131189 & GGGCTACCAGTGCACCTTTG & GATGATAGCTCTGCGTCGAGTC & 76 & 1.91 \\
\hline dnmt3aa & DNA (cytosine-5-)-methyltransferase $3 \mathrm{~A}$ & DNA methylation & NM_001018134 & GGCGCCTGTTCTTGAGTT & TCACTGACCCCCATTGCAA & 112 & 1.91 \\
\hline dnmt3b & DNA (cytosine-5-)-methyltransferase 3B & DNA methylation & NM_001020476 & AGGTTGGAACCTCCCGAAA & TGCGCACAGGTAACAAATGG & 115 & 1.94 \\
\hline cbs & Cystathionine-beta-synthase & Transsulfuration & NM_001111232 & CTITGCCCTGGTGGTTCATG & АССАСТССАAАСАССАТТТС & 81 & 2.00 \\
\hline mgmt & $\begin{array}{l}\text { O-6-methylguanine-DNA } \\
\text { methyltransferase }\end{array}$ & DNA repair & NM_001256243 & TCCACCCTGTTGTCCTGTCA & GATGTAAGGCAGGCAGAGGAA & 117 & 2.03 \\
\hline pgrme1 & $\begin{array}{l}\text { Progesterone receptor membrane } \\
\text { component } 1\end{array}$ & $\begin{array}{l}\text { Glucose/energy } \\
\text { metabolism }\end{array}$ & NM_001007392 & TITCACGTCGCCACTGAAC & СTCCTCAACCGGGCCATAGT & 104 & 1.90 \\
\hline cyp1a1 & $\begin{array}{l}\text { Cytochrome P450 family } 1 \text { subfamily A } \\
\text { member } 1\end{array}$ & Detoxification & AF210727 & GGTGTTGGTITCGGTTGG & GGCATCCCGGTGAACTTTAA & 114 & 1.99 \\
\hline $\operatorname{vtg} 1$ & Vitellogenin 1 & Endocrine disruption & NM_001044897 & GTCATCAATGAGGATCCAAAGGCCA & GCCTCAGCGATCAGTGCACCAT & 209 & 1.91 \\
\hline esr1* & Estrogen receptor 1 & Endocrine disruption & NM_152959 & AAACACAGCCGGCCCTACAC & GCCAAGAGCTCTCCAACAAC & 157 & 2.12 \\
\hline esr2a* & Estrogen receptor $2 \mathrm{a}$ & Endocrine disruption & NM_180966 & TGATCAGCTGGGCCAAGAAG & GATTAACGGAGCGCCACATC & 123 & $2.00^{* *}$ \\
\hline ar & Androgen receptor & Endocrine disruption & NM_001083123 & GGATGAGGTCGGAGCAGTTC & GGCTCAATGGCCTCCAGAAT & 117 & 2.03 \\
\hline cyp19a2 & $\begin{array}{l}\text { Cytochrome P450 family } 19 \text { subfamily } \\
\text { A member } 2\end{array}$ & Endocrine disruption & AF406756 & GAGCGGGCAGGACATAGTGT & GCTTGGGCTCAATCACTCTCA & 89 & 2.10 \\
\hline fos & Fos proto-oncogene & $\begin{array}{l}\text { Cell proliferation, } \\
\text { differentiation and } \\
\text { transcription regulation }\end{array}$ & NM_205569 & GGGTATTACCCGCTCAACCA & CAAGTCCGGGCATGAAGAGA & 102 & 2.02 \\
\hline mapk1 & Mitogen-activated protein kinase 1 & $\begin{array}{l}\text { Cell proliferation, } \\
\text { differentiation and } \\
\text { survival }\end{array}$ & NM_182888 & TACATCGGAGGAGGCGCTTA & GCTCAAACGGGCTGATCTTC & 94 & 1.99 \\
\hline casp3a & Caspase 3A & Apoptosis & NM_131877 & CCCAGATGGTCGTGAAAGGAT & TGAACCATGAGCCGGTCATT & 107 & 2.07 \\
\hline eef1a1 & $\begin{array}{l}\text { Eukaryotic translation elongation factor } \\
1 \text { alpha } 1\end{array}$ & Refgen & AY422992 & AGACAACCCCAAGGCTCTCA & CTCATGTCACGCACAGCAAA & 126 & 2.06 \\
\hline uba52 & $\begin{array}{l}\text { Ubiquitin A-52 residue ribosomal } \\
\text { protein fusion product } 1\end{array}$ & Refgen & NM_001037113 & CGAGCCTTCTCTCCGTCAGT & TTGTTGGTGTGTCCGCACTT & 126 & 2.08 \\
\hline actb & Beta-actin & Refgen & AF057040 & CGAGCAGGAGATGGGAACC & CAACGGAAACGCTCATTGC & 102 & 2.08 \\
\hline
\end{tabular}

*PCR primers obtained from Sawyer et al. (2006). **PCR efficiency set to 2.00 . 


\section{Whole-Genome Bisulfite Sequencing (WGBS)}

Bisulfite sequencing was used to identify methylated genomic regions after BPA exposure. Genomic DNA (gDNA) was extracted from five groups of control zebrafish embryos and five groups of embryos exposed to $10 \mu \mathrm{M}$ BPA for $72 \mathrm{~h}$ (from 24 to $96 \mathrm{hpf}$ ). The exposure concentration was selected to reflect a sublethal but relatively high dose expected to give behavioral effects using locomotor variant 4 treatment. Each group consisted of pools of 20 embryos. gDNA extraction was conducted with the AllPrep DNA/RNA Mini Kit (Qiagen, Hilden, Germany). After quality validation, and addition of positive control DNA, the gDNA (5 $\mu \mathrm{g})$ was fragmented to obtain insert size of 200-300 bp with the Covaris S220 Focused-ultrasonicator (Covaris, Woburn, MA, United States). Fragment terminal repair, A-ligation and methylation sequencing adapter ligation were then conducted, using the TruSeq DNA Library Preparation Kit (Illumina, San Diego, CA, United States). Bisulfite treatment was conducted with the EZ DNA Methylation Gold Kit (Zymo Research, Irvine, CA, United States). The ligation products were then purified and size-selected by agarose gel electrophoresis. Bisulfite-treated DNA was subsequently PCR-amplified to enrich both-end adapter fragments. Library concentration was first quantified by Qubit 2.0, and then diluted to $1 \mathrm{ng} / \mu \mathrm{l}$ before checking insert size on the Agilent 2100 Bioanalyzer (Agilent Technologies, Palo Alto CA, United States), followed by more accurate quantification by qPCR (effective concentration of library $>2$ $\mathrm{nM}$ ). Final paired-end sequencing of pooled libraries was done using the HiSeq 4000 platform (Illumina, San Diego, CA, United States).

\section{WGBS Analysis Pipeline}

Quality assessment was completed on raw reads using FastQC 0.11.5 (Andrews, 2016). Adapters and reads under a phred score of 30 were quality trimmed using Trim Galore 0.4.4 (Krueger, 2015). Reads were aligned to the Ensembl Danio rerio genome GRCz10 release 87 (Yates et al., 2016) using Bismark 0.18.1 (Krueger and Andrews, 2011). Methylation calling was also completed using Bismark, using the 'bismark_methylation_extractor' tool. Three bases were additionally excluded from the $3^{\prime}$ end of each read using the -ignore_3prime and -ignore_3prime_r parameters, to counter methylation bias resulting from the use of unmethylated cytosines in the end-repair step during library preparation.

\section{Statistics}

GraphPad Prism 6.0 software (GraphPad Software, Inc., San Diego, CA, United States) and Statistica 8.0; 2008 (Statsoft Inc., Tulsa, OK, United States) were used for statistical analyses of the transcriptional data. One-way ANOVA with Tukey's (behavior) or Dunnett's (transcription) multiple comparisons was used to analyze for possible effects of BPA. In case Bartlett's test showed that the variances differed, the MNE data were log-transformed before ANOVA analysis. Outliers, as detected by the ROUT method (ROUT Q $=1 \%$ ), were omitted from the transcriptional dataset. The ROUT method is based on the False Discovery Rate (FDR). With $Q=1 \%$, no more than $1 \%$ of the identified outliers are false. A significance level of $P<0.05$ was used for all tests.

Downstream analysis and generation of figures for methylation data were completed using R ( $\mathrm{R}$ Core Team, 2016). DM sites were identified using methylKit (Akalin et al., 2012). Genomic features were annotated using genomation (Akalin et al., 2015) and GenomicRanges (Lawrence et al., 2013) packages. Promoter regions were defined as $1,000 \mathrm{bp}$ upstream and downstream from transcription start sites. Gene identifiers were annotated using biomaRt (Durinck et al., 2009). All analysis after methylation calling was based on CpG context. DAVID 6.8 was used to identify enriched KEGG pathways (Huang et al., 2009). Global methylation was also represented as a Circos plot (Krzywinski et al., 2009), based on mean hyper and hypomethylation per $10 \mathrm{Mbp}$ tiles.

\section{RESULTS}

\section{Larval Deformities}

No differences $(p>0.05)$ were found between controls (E3 media), DMSO vehicle controls or treatments for rates of hatch, survival or total deformities (Figures 1A-C). A small but statistically significant $(p<0.05)$ increase occurred in the rates of pericardial edema in embryos from the highest $(30 \mu \mathrm{M}) \mathrm{BPA}$ exposure treatment at $24 \mathrm{hpf}(1.8 \pm 0.9 \%$ vs. $0 \%$ in other groups $)$ but not at later stages (Figure 1D).

\section{Larval Locomotor Activity}

No differences in locomotor activity were identified at $3 \mathrm{dpf}$. At $4 \mathrm{dpf}$, a positive linear response in the percentage of time larvae were hyperactive was identified under light (dark line, linear regression, slope non-zero, $P=0.044$ ) but not dark conditions (locomotor analysis variant 1, Figure 2A). When exposed to $1 \mathrm{~s}$ dark flashes (locomotor analysis variant 2), larvae exposed to $0.001 \mu \mathrm{M}$ BPA were active for a larger percent of time over the entire analysis period than those exposed to $1.0 \mu \mathrm{M}$ BPA (7.0 vs. $2.1 \%$ of time, 3.4-fold difference, $p<0.05$, Figure 2B), but no other differences were observed. No differences between treatments were observed in larvae exposed to a regime of shorter $(0.5 \mathrm{~s})$ dark flashes at $4 \mathrm{dpf}$ or $5 \mathrm{dpf}$ (locomotor analysis variant 3 , data not shown). At 5 dpf larvae exposed to $0.001 \mu \mathrm{M}$ BPA initiated low and medium levels of activity more often (1.6-fold) than those exposed to $0.0001 \mu \mathrm{M}$ BPA under light but not dark conditions (Figures 3A,B). The amount of time that larvae were active at medium activity levels was also higher (1.7-fold) in larvae exposed to 0.001 versus $0.0001 \mu \mathrm{M}$ BPA (Figure 3C). The locomotor activity of $5 \mathrm{dpf}$ larvae that were developmentally exposed to zero or the three highest concentrations of BPA (1, 10 , and $30 \mu \mathrm{M}$ ) were also analyzed in 12 well plates to explore effects under conditions of greater liberty for free movement (locomotor analysis variant 4). Larvae with more room to move demonstrated a positive linear response for time spent moving at low speeds in the dark, but not light conditions 
A

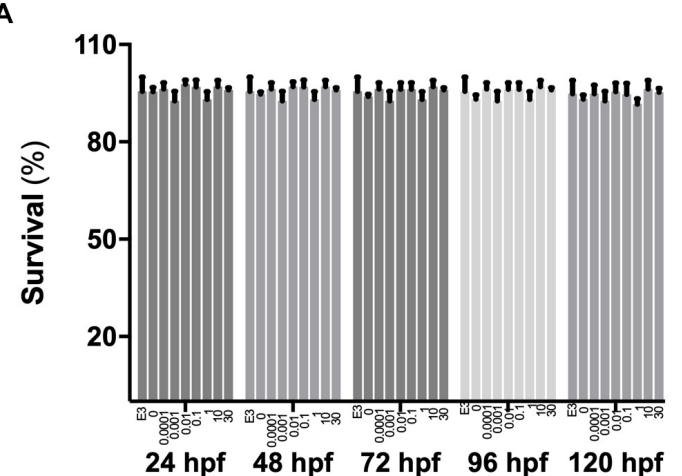

C

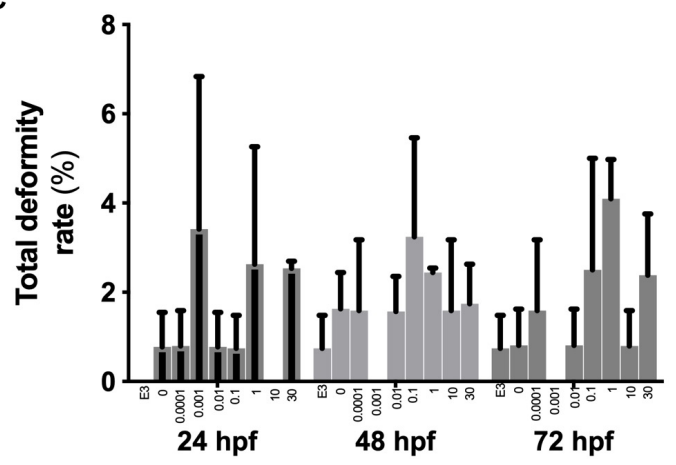

B

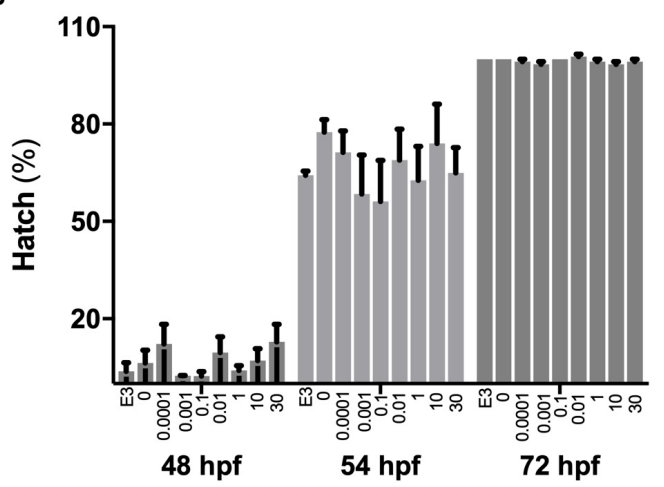

D

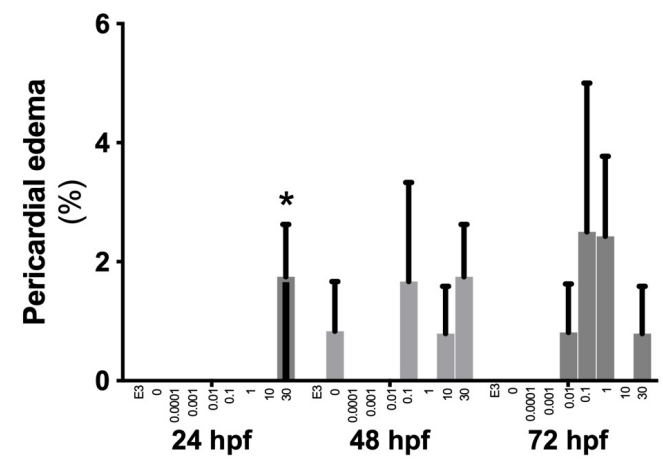

FIGURE 1 | The effects of BPA on zebrafish embryo survival, hatch and rates of deformities. Survival (A), hatch rates (B) and rates of total deformities (C) or pericardial edema (D) in zebrafish embryos when exposed from 2 to $26 \mathrm{hpf}$ to increasing concentrations of BPA. Bars within each time period group represent mean $\pm \mathrm{SEM}, n=3$ of E3 controls, DMSO controls, 0.0001, 0.001, 0.01, 0.1, 1, 10, and $30 \mu \mathrm{M}$ BPA (left to right). Asterisk indicates statistical differences in mean values between treatments (one-way ANOVA, Tukey post hoc test, $p<0.05$ ).
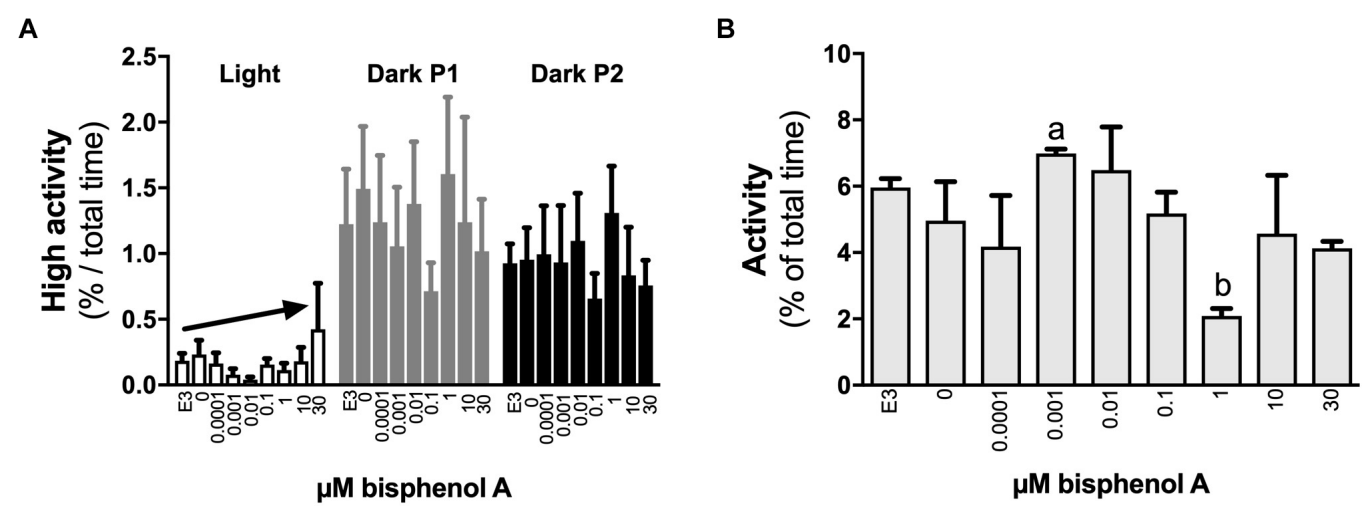

FIGURE 2 | The effects of early developmental exposure to BPA on zebrafish embryo locomotor activity at 4 dpf. The amount of time (\% of total) that 4 dpf zebrafish larvae were hyperactive (A) or active in general (B) when exposed to different light conditions after aqueous exposure to graded levels of BPA (0-30 $\mu$ M) between 2 and 26 hpf. Light conditions in (A) were 5 min full light (open bars) followed by two sequential 5 min periods of darkness (dark P1 and P2, gray or black bars; see locomotor analysis variant 1 in methods). Light conditions in (B) were $1 \mathrm{~s}$ of dark (dark flash) followed by $9 \mathrm{~s}$ of full light, repeated three times (total of $30 \mathrm{~s}$ ), and the data presented are the average responses over the $30 \mathrm{~s}$ period (see locomotor analysis variant 2 in methods). Solid arrows represent linear responses to increasing BPA exposure concentrations ( $p<0.05$, graph $\mathbf{A}, y=0.12+0.01 x, R^{2}=0.17$ ). Letters indicate statistical differences in mean values between treatments (one-way ANOVA, Tukey post hoc test, $p<0.05$ ). Data are the mean \pm SEM, $n=3$, where each replicate is the average of $8-24$ larvae.

(Figure 4A, $P=0.039)$. Negative linear responses to BPA exposure concentrations in the amount of time spent moving at high speeds (Figure 4B, $P=0.039$ ). and the number of times medium (Figure 4C, $P=0.035$ ) and high (Figure 4D, $P=0.030$ ) speed activity was initiated were found under dark but not light conditions. 
A

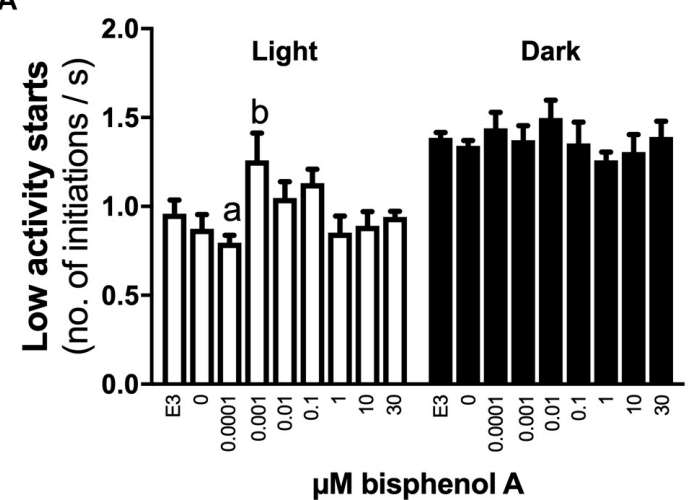

B

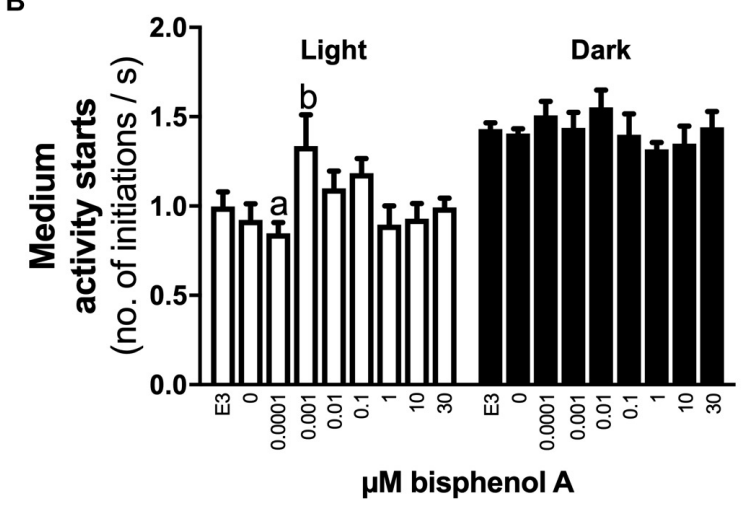

C

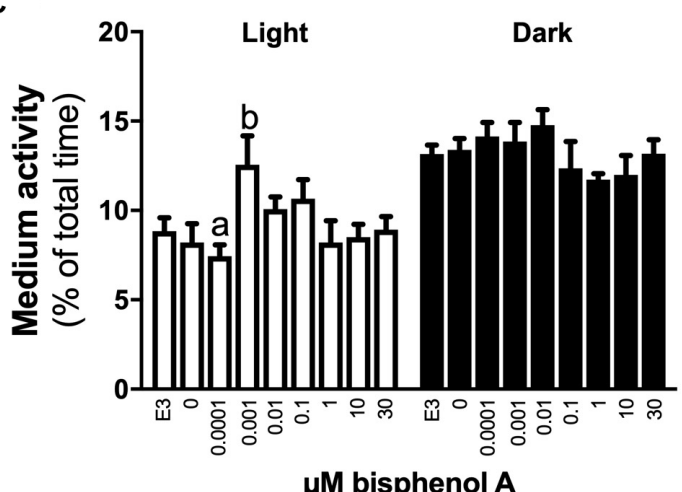

FIGURE 3 | The effects of early developmental exposure to BPA on zebrafish embryo locomotor activity at 5 dpf. The amount of time (\% of total) that 5 dpf zebrafish larvae initiated low (A) or medium (B) levels of activity, and the time medium levels of activity were undertaken (C), under either light (open bars) or dark (black bars) after aqueous exposure to graded levels of BPA $(0-30 \mu \mathrm{M})$ between 2 and 26 hpf. Letters indicates statistical differences in mean values between treatments (one-way ANOVA, Tukey post hoc test, $p<0.05$ ). Data are the mean $\pm \mathrm{SEM}, n=3$, where each replicate is the average of 8-24 larvae.

\section{BPA-Induced Effects on Gene Expression}

Significant effects on transcription were seen for 11 out of the 15 examined genes. Several genes were down-regulated at $0.01 \mu \mathrm{M}$ BPA or higher exposure concentrations. Genes encoding proteins involved in apoptosis (casp3, Figure 5A), detoxification (cypla1, Figure 5B), endocrine disruption (esr $2 a$, Figure 5F), DNA methylation (dnmt1, Figure 5J) and cysteine synthase activity (cbs, Figure 5M) had all lower expression at $0.01 \mu \mathrm{M} \mathrm{BPA}$ or higher concentrations. Responding to even lower concentration, fos, encoding a protein also linked to apoptosis, was down-regulated at $0.001 \mu \mathrm{M}$ BPA (Figure 5C).

The expression of several genes had a non-linear concentration-response to BPA exposure. A pattern of stimulation at lower concentrations followed by inhibition at higher concentrations was observed for ar, esr1, mapk1, $d n m t 3 b$ and $c b s$ (Figures 5D,E,H,L,M). Pattern-wise, two genes showed stimulation at medium exposure concentrations (mgmt, Figure 5N and cyp19a2, Figure 50), while pgrmc1 displayed medium concentration inhibition (Figure 5I). At the transcriptional level, BPA therefore seems to induce distinct responses at $0.01 \mu \mathrm{M}$ or higher concentrations for genes linked to DNA methylation, endocrine disruption, detoxification and cell survival.

\section{BPA-Induced Effects on DNA Methylation Read Quality and Mapping Rate}

An exposure concentration of $10 \mu \mathrm{M}$ BPA was selected for identification of methylated genomic regions with WGBS based on the behavioral and transcriptional responses. About $50 \mathrm{~Gb}$ (range 41-59 Gb) of raw data was generated from each of the five BPA-treated and five control samples (between 140 and 190 million reads per sample). Bisulfite conversion was $99.3 \%$ or higher for all samples. A mean of $96.4 \%$ of bases had quality scores greater than Q20 and 91.4\% scored greater than Q30. Alignment to the GRCz10 zebrafish reference genome yielded a mean mapping rate of $66.4 \%$.

\section{Methylation Patterns}

Global methylation was $9.0 \%( \pm 0.07 \%)$ for the BPA treated group and $9.2 \%( \pm 0.09 \%)$ for the control group, though the difference wasn't significant $(p=0.1)$. Methylation was highest in the CpG context, with $81.7 \%$ of $\mathrm{CpG}$ sites methylated across all samples. Cytosines in $\mathrm{CHG}$ and $\mathrm{CHH}$ contexts were each $0.7 \%$ methylated. Of these $\mathrm{CpG}$ methylated sites, 
A

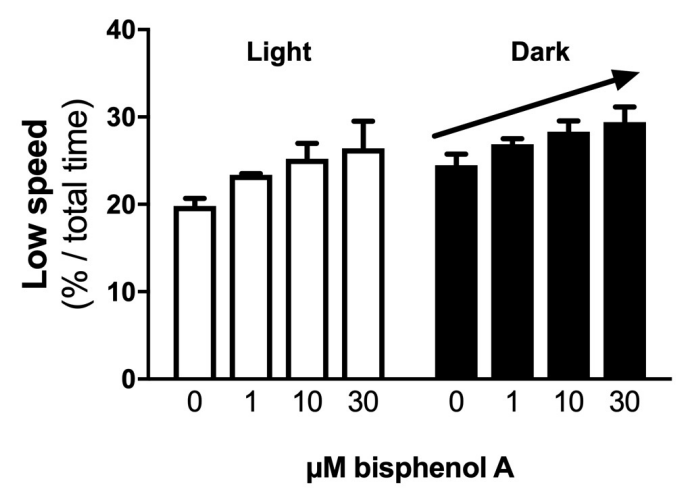

C

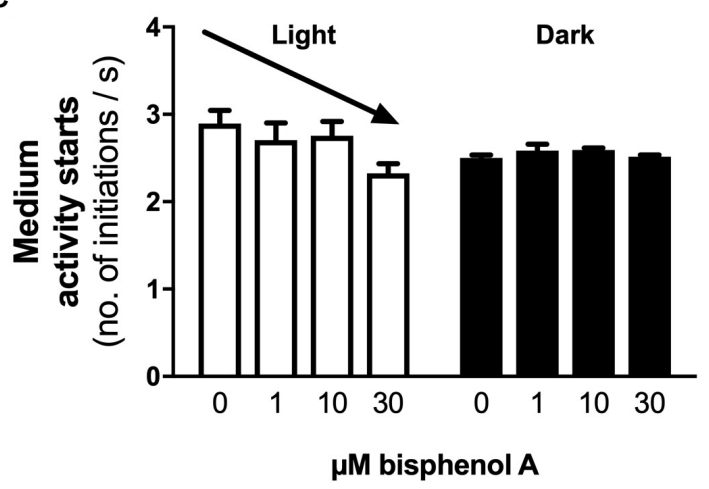

B

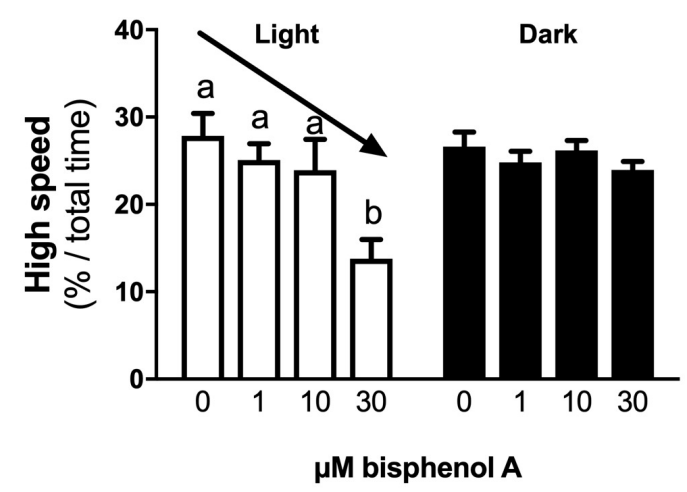

D

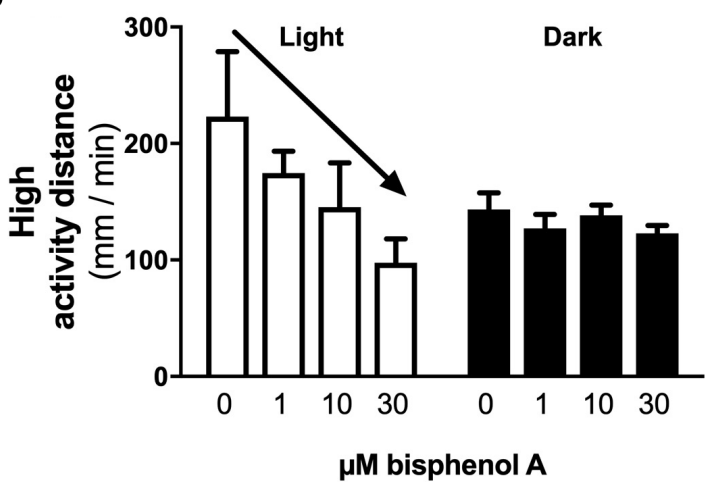

FIGURE 4 | The effects of early developmental exposure to BPA on zebrafish embryo locomotor activity in large wells at 5 dpf (Variant 4 , see methods). The amount of time (\% of total) that $5 \mathrm{dpf}$ zebrafish larvae moved at low (A) or high (B) speeds, the number of times zebrafish larvae initiate medium (C) levels of activity, and the distance covered when moving at high speeds (D), under either light (open bars) or dark (black bars) after aqueous exposure to graded levels of BPA (0-30 $\mu \mathrm{M}$ ) between 2 and 26 hpf. Solid arrows represent linear responses to increasing BPA exposure concentrations $\left(p<0.05\right.$, graph $\mathbf{A}, y=26.0+0.13 x, R^{2}=0.36$; graph $\mathbf{B}, y=27.1-0.43 x, R^{2}=0.65$; graph $\mathbf{C}, y=2.8-0.016 x, R^{2}=0.40$; graph $\left.\mathbf{D}, y=196-3.5 x, R^{2}=0.37\right)$. Letters indicates statistical differences in mean values between treatments with ANOVA (one-way ANOVA, Tukey post hoc test, $p<0.05$ ). Data are the mean \pm SEM, $n=3$, where each replicate is the average of 3 larvae.

20,474 sites (18.5\% of global CpG methylated sites) were differentially methylated (DM) between BPA treated and control groups, though DM hypermethylated sites (10,981 sites, $9.9 \%$ of global $\mathrm{CpG}$ methylated sites) were slightly more numerous than hypomethylated $(9,493,8.5 \%)$ (Figure 6). Total DM and hyper/hypomethylation was variable between chromosomes (Figure 7). Chromosome 25 and chromosome 16 had the fewest hypermethylated and hypomethylated sites respectively (47 regions each). Chromosomes 10 and 24 had the greatest number of hyper and hypomethylated sites with 1,509 and 1,462 sites respectively.

Most DM sites fell within introns (12,159 sites) or intergenic regions (8,055 sites) (Figure 8). Promoter regions contained 1,472 DM sites, 1,634 DM sites fell within CpGi flanks, 699 fell within coding regions, 439 fell within $3^{\prime}$ untranslated regions, 64 fell within CpG islands, 98 fell within 5'UTRs and 13 were on splice junctions. Reflecting global methylation, hypermethylated sites were more numerous within introns (53.9\% of intron DM sites), intergenic regions (54.2\%), CpGi flanks (53.8\%), coding regions (55.9\%), 3'UTRs (61.3\%) and CpG islands (54.7\%), though hypomethylation was slightly higher in $5^{\prime}$ UTRs (54.1\%) and on splice junctions (61.5\%). Only $0.6 \%$ of CpG islands (CpGi) found within the zebrafish genome were DM. However, 11.3\% of the CpGi flanking regions (1,000 bp up and downstream) contained DM sites, which was slightly elevated compared to the 9.1\% DM level found over the whole genome.

\section{Genes and Metabolic Pathways}

Of the 20,474 DM sites, 13,739 of these annotated to zebrafish genes. However, as many genes contain multiple DM sites, the total number of genes containing DM sites was 4,873 (Supplementary Table S1). There were 49 genes containing $\geq 20$ DM sites (Table 2). Of particular significance are the protocadherin 2 gamma subfamily genes, which represent the top seven genes ( $p c d h 2 g 1,3,5,6,7,8,9$ ), in terms of total number of DM sites per gene and seven out of the nine genes that have more than 50 DM sites. In addition, $p c d h 2 g 12$ and 13 both contained 29 DM sites and $p c d h 2 g 17$ had 24 DM sites.

Four KEGG pathways were enriched $(p<0.01$, Benjamini < 0.05) for genes containing DM sites: The phosphatidylinositol signaling system (46 genes), VEGF signaling pathway (32 genes), MAPK signaling pathway (89 genes) and Inositol phosphate metabolism (30 genes) (Table 3). A list of DM genes for each significant KEGG pathway is in 
A

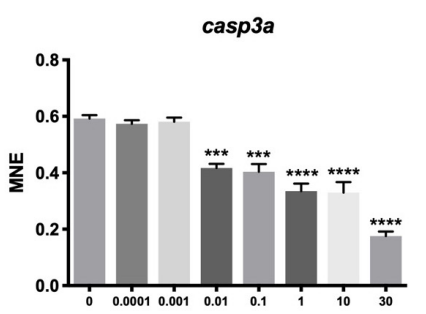

D

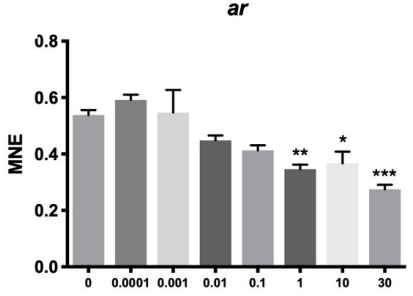

G

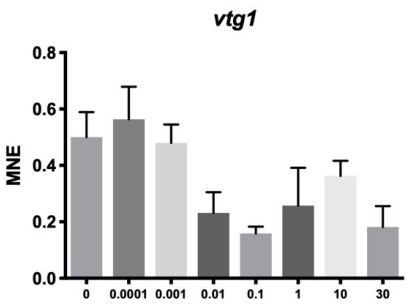

J

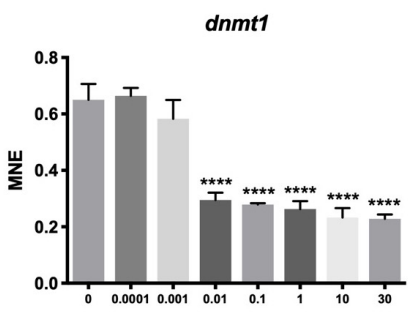

M

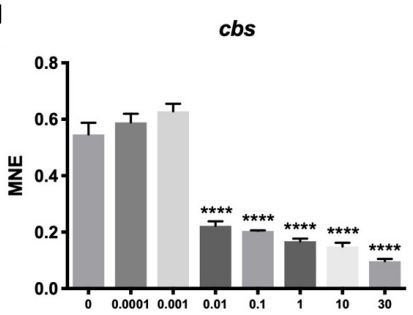

B

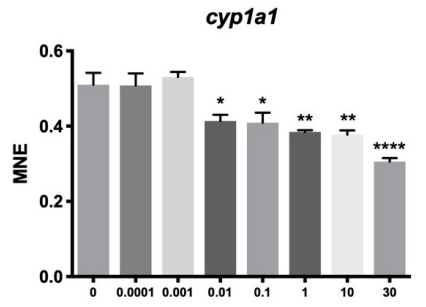

E

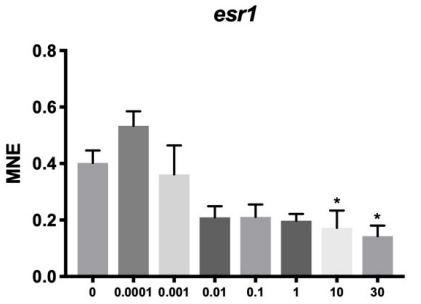

H

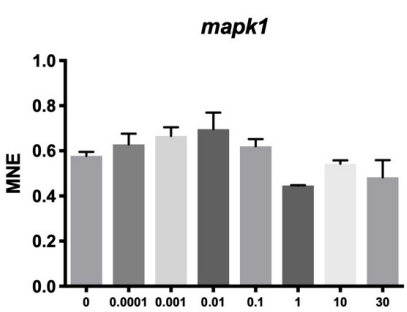

K

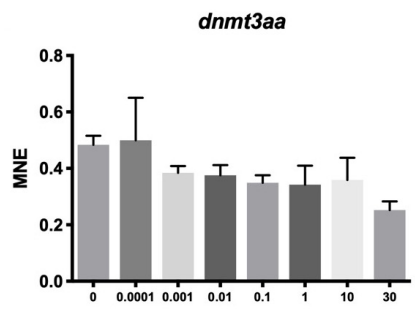

$\mathbf{N}$

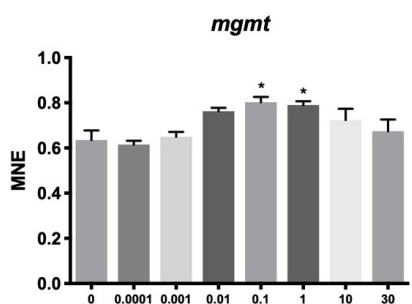

C

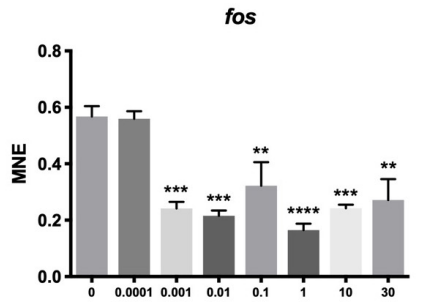

F

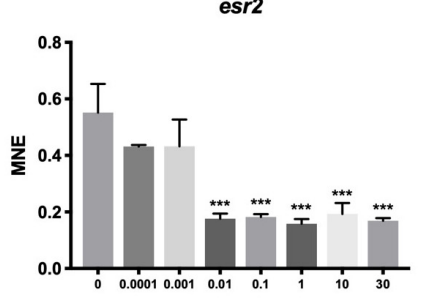

I

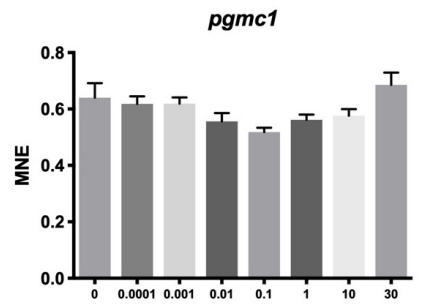

$\mathbf{L}$

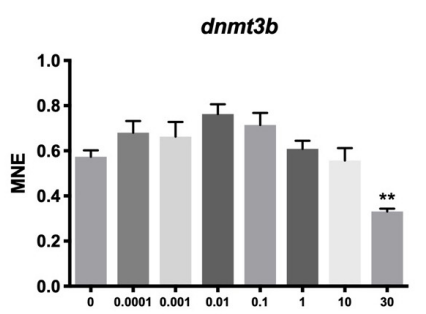

0

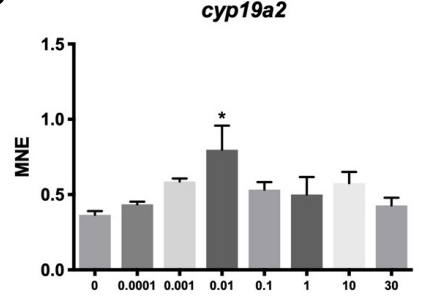

FIGURE 5 | Transcriptional effects of BPA on zebrafish embryos. Concentration-response effects of BPA on selected genes encoding proteins linked to apoptosis $(\mathbf{A}, \mathbf{C}, \mathbf{N})$, detoxification $(\mathbf{B})$, reproduction $(\mathbf{D}-\mathbf{G}, \mathbf{O})$, proliferation and differentiation $(\mathbf{H})$, steroidogenesis $\mathbf{( I )}$, DNA methylation $(\mathbf{J}-\mathbf{L})$ and cysteine synthase activity $(\mathbf{M})$. Asterisk indicates statistical differences in mean values between DMSO controls and exposed embryos with ANOVA (one-way ANOVA, Dunnett's post hoc test, $\left.{ }^{*} p<0.05,{ }^{* *} p<0.01,{ }^{* * *} p<0.001,{ }^{* * * *} p<0.0001\right)$. Data are the mean $\pm \mathrm{SEM}, n=3$, where each replicate is the average of 40 larvae. E3 control not shown. 


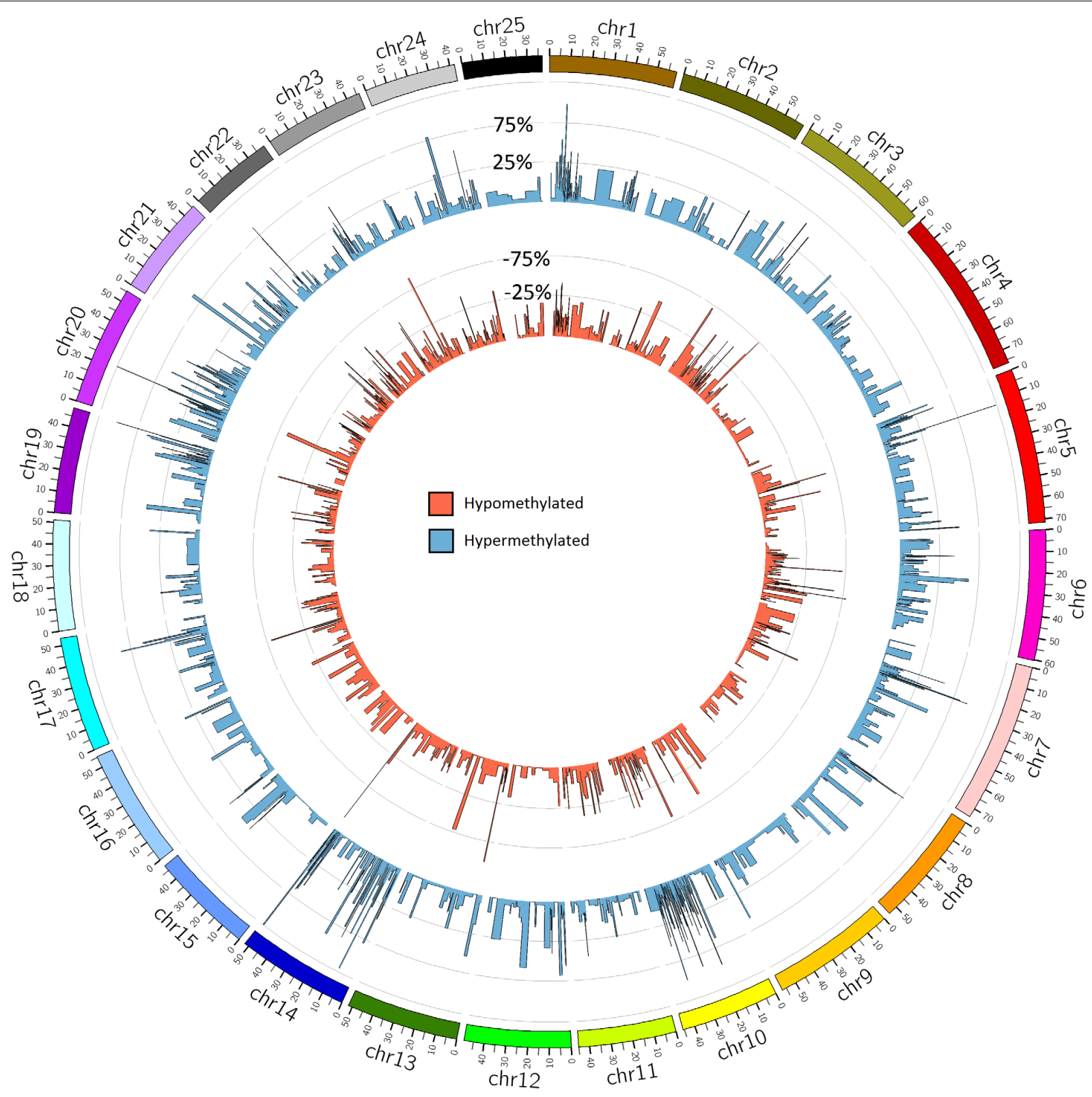

FIGURE 6 | Global methylation patterns in zebrafish embryos exposed to $10 \mu \mathrm{M}$ BPA from 24 to 96 hpf. Differentially methylated regions in zebrafish embryos exposed to BPA compared to controls. The blue circular bar plot represents percent of hypermethylation and the red circular bar plot shows percent of hypomethylation per region (Q-value $<0.01$ and methylation difference $>25 \%$ ). DM regions in this figure are mean DM per 10 Mbp window.

Supplementary Table S2. Other metabolic pathways that weren't significantly enriched, but featured numerous genes with DM sites included Wnt signaling pathway with 50 genes $(p=0.005)$, focal adhesion $(n=69, p=0.005)$, vascular smooth muscle contraction $(n=42, p=0.02)$, adherens junction $(n=31$, $p=0.02)$, notch signaling pathway $(n=20, p=0.02)$, ErbB signaling pathway $(n=32, p=0.03)$, endocytosis $(n=84$, $p=0.04)$ and insulin signaling pathway $(n=46, p=0.04)$.

There were several linkages between gene expression and differential methylation results. Each identified DM site, along with the genome coordinates and genomic feature each site falls within, are listed in Supplementary Table S1. Note that a single DM site may sometimes fall within more than one genomic feature, due to overlapping defined genomic regions per feature. Dnmt3aa was hypomethylated at three cytosines, two in introns, and one in the promoter region, but did not show differential gene expression (Figure 5K). Two $d n m t 3 b$ duplicate genes, dnmt3ba and dnmt3bb.1, contained DM sites: dnmt3ba contained two hypomethylated sites, one in the coding, and one in the $3^{\prime}$ UTR region and $d n m t 3 b b .1$ contained one hyper and two hypomethylated sites in introns. Pgrmc1 was hypermethylated in a single promoter region. Cyp1a1 and cyp19a2 didn't contain any 


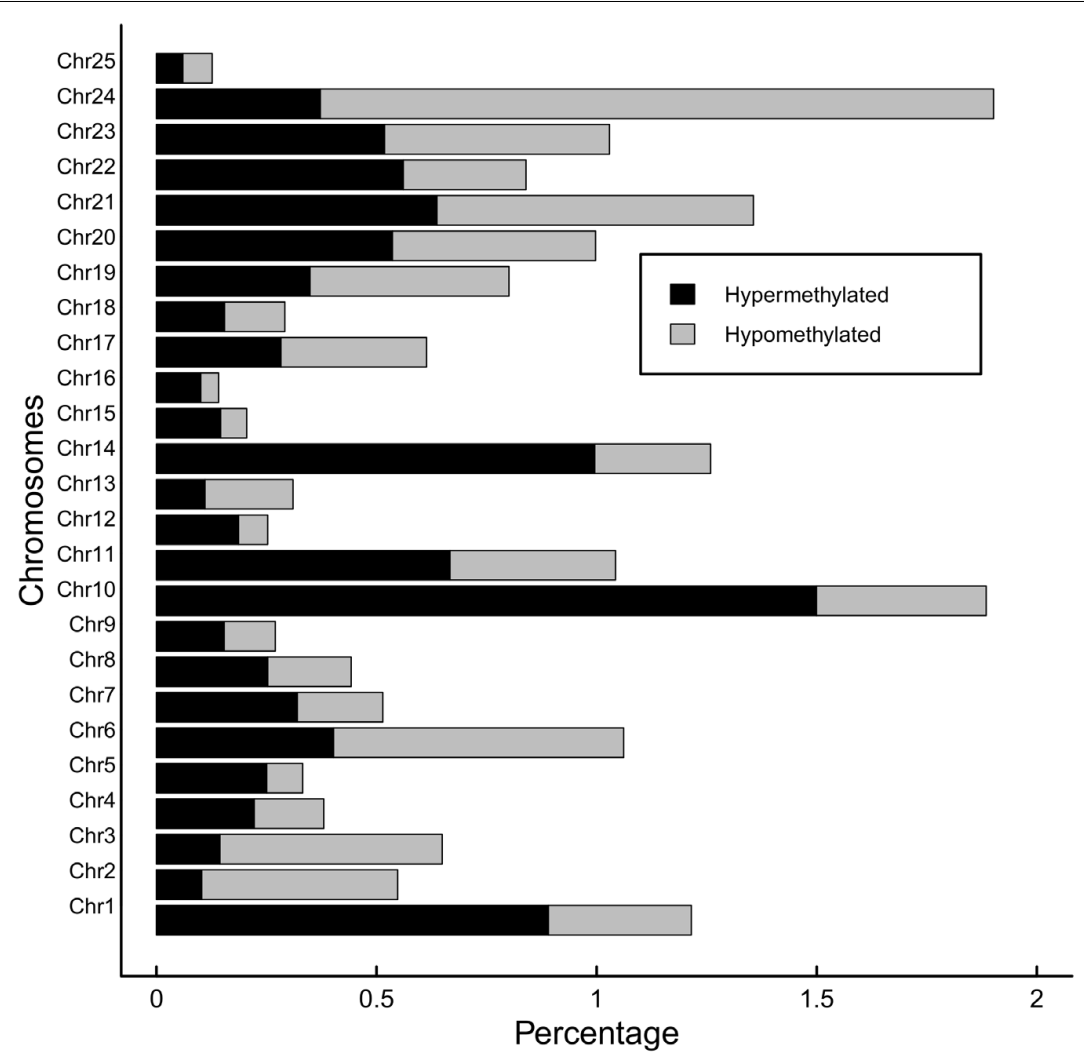

FIGURE 7 | Hypermethylation and hypomethylation per chromosome in zebrafish embryos exposed to $10 \mu \mathrm{M}$ BPA from 24 to 96 hpf. Percentage of hypermethylated sites per chromosome are shaded black and percentage of hypomethylated regions is gray. Cutoff for differentially methylated sites is $Q$-value $<0.01$ and methylation difference $>25 \%$.

A

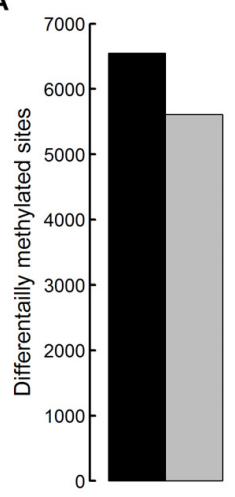

Introns

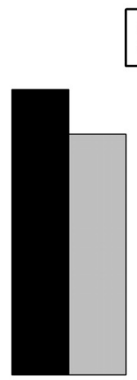

Intergenic
- Hypermethylated
Hypomethylated

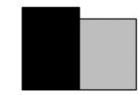

CpGi Flank

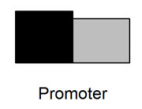

Promoter
B

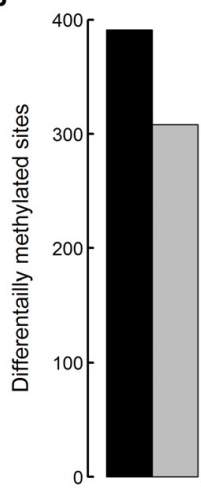

Coding

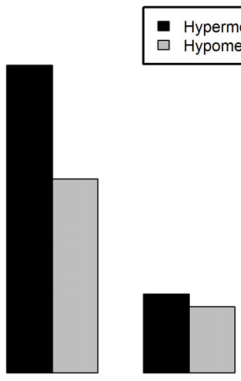

$\mathrm{CpGi}$

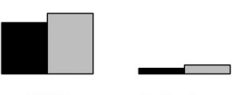

Splice junct

Genomic features

FIGURE 8 | Differentially methylated sites per genomic feature in zebrafish embryos exposed to $10 \mu \mathrm{M}$ BPA from 24 to 96 hpf. Counts of hypermethylated sites (black) and hypomethylated sites (gray) in (A) introns, intergenic regions, CpG island flanks, promoter regions and (B) coding, $3^{\prime}$ untranslated regions, CpG islands, 5' untranslated regions and splice junctions.

DM sites, but four other cytochrome P450 genes did: cyp2v1, cyp2ad2, cyp2p10, cyp2p7, all which contained hypermethylated cytosines within introns. Esr $2 a$ contained seven hyper and hypomethylated sites, five within in introns and two within promoter regions and esrra contained three hypermethylated sites, two in introns and one in the promoter region. Fos was not DM but fosl2, a zebrafish fos-like antigen, contained one hypomethylated sites in the $3^{\prime}$ UTR region. Mapk 1 contained two hypermethylated sites and one hypomethylated site, all within introns. Several other mitogen-activated protein kinases (and 
TABLE 2 | Genes containing $\geq 20$ differentially methylated sites.

\begin{tabular}{|c|c|}
\hline Gene symbol & DM sites \\
\hline pcdh2g1 & 68 \\
\hline pcdh2g6 & 62 \\
\hline pcdh2g5 & 62 \\
\hline pcdh2g3 & 62 \\
\hline pcdh2g7 & 60 \\
\hline pcdh2g8 & 60 \\
\hline pcdh2g9 & 59 \\
\hline BX005294.2 & 59 \\
\hline si:dkey-33o22.1 & 57 \\
\hline$s d k 1 b$ & 44 \\
\hline$n t m$ & 41 \\
\hline ctdp1 & 36 \\
\hline cntnap2a & 36 \\
\hline$D \lg 2$ & 34 \\
\hline pcdh1g1 & 32 \\
\hline KIf3 & 31 \\
\hline cux1a & 31 \\
\hline pcdh2g13 & 29 \\
\hline pcdh2g12 & 29 \\
\hline si:ch211-165d12.4 & 28 \\
\hline cdh 4 & 27 \\
\hline csmd3 & 27 \\
\hline magi1b & 26 \\
\hline msi2a & 26 \\
\hline ebf1b & 26 \\
\hline stau2 & 25 \\
\hline dpp6a & 25 \\
\hline pcdh2aa15 & 25 \\
\hline pcdh1g2 & 25 \\
\hline dmd & 24 \\
\hline ncoa2 & 24 \\
\hline kcnh5a & 24 \\
\hline pcdh1a3 & 24 \\
\hline pcdh2g17 & 24 \\
\hline ralgapa2 & 23 \\
\hline nrxn2a & 23 \\
\hline cadpsb & 23 \\
\hline pard3b & 23 \\
\hline dacha & 22 \\
\hline nudt14 & 22 \\
\hline cadm2a & 21 \\
\hline uvrag & 21 \\
\hline pcdh1g3 & 21 \\
\hline vps50 & 20 \\
\hline myrip & 20 \\
\hline tmem88a & 20 \\
\hline irrc7 & 20 \\
\hline pcdh2ab6 & 20 \\
\hline pcdh1gb2 & 20 \\
\hline
\end{tabular}

mapk interacting and associated proteins) were DM, including mapk11, mapk14a, mapk15, mapk4, mapk7, mapk8ip2, mapk8ip3, mapkap1, mapkbp1 and mapkapk2a. All of these MAPK genes were DM within introns, with the exception of mapk7, which contained a DM site within the promoter region and mapk4, with a site within the coding region. Caspase 3a (casp3a) contained no DM sites but three other caspases, also involved in apoptosis, were DM: casp3b, casp6l1, casb811. Casp611 was hypomethylated in the promoter region and the other caspase genes were DM in introns.

In the current state of epigenetics research, the functional association between methylation and gene expression is primarily associated with methylation within promoter regions, which has been shown to modify (typically suppress) gene expression. The 1,472 DM sites within promoter regions annotated to 1,147 unique genes (Supplementary Table S3). There were no significantly enriched KEGG pathways, but three pathways contained several genes with promoters containing DM. RNA transport contained 18 genes $(p=0.003)$, lysosome 15 genes $(p=0.02)$ and mRNA surveillance pathway 10 genes $(p=0.04)$.

\section{DISCUSSION}

Associations between contaminant exposure and behavioral effects can rely on altered transcription. Saili et al. (2013) linked hyperactivity observed in zebrafish embryos exposed to $0.1 \mu \mathrm{M}$ BPA, but not at $80 \mu \mathrm{M}$ BPA, to altered expression of nervous system genes. More specifically, many genes belonging to the ERK/MAPK signaling and tight junction signaling pathways, which are important in nervous system functioning, were differentially expressed. Of biological functions associated with exposure to $0.1 \mu \mathrm{M}$ BPA, many described nervous system development or morphology, and 23 genes were included in the "development of central nervous system" function (Saili et al., 2013). Significantly DM sites were observed for several of these genes in this study (apaf1, asic2, ift172, plxna4, and $r f \times 4)$, as well as genes closely related to other genes listed in the Saili et al. (2013) study (celsr1b, nlgn1, nlgn2a, nlgn2b, $n l g n 3 a, n \operatorname{lgn} 4 b$, plxna1a, rfxap, slc1a1, slc1a3b, and slc1a7a). Of these, apaf1 and nlgn $2 b$ showed DM sites within the promoter region. Though asic2 DM sites only fell within introns, the large number of DM sites (21) which were all hypomethylated is too significant a trend to ignore. Asic2 is functionally relevant, affecting broad neuronal processes and playing a key role in behavioral responses to deleterious stimuli (Price et al., 2014). The exact mechanisms whereby gene body methylation affects gene expression remain unknown, however, this present study provides substantial correlative evidence, further reinforcing the current scientific viewpoint that gene body methylation plays a significant role. Regarding these genes that contained DM sites within promoter regions: apaf1 is a key transcriptional target that regulates post neural injury apoptosis and neurodegeneration (Fortin et al., 2001) and $n \operatorname{lgn} 2 b$ contained two DM sites within its promoter region and six sites within introns, and is a member of the neuroligins gene family, which are involved in the excitation and inhibition of CNS synapses (Rissone et al., 2010). DM sites of these genes observed at $10 \mu \mathrm{M} \mathrm{BPA}$ in this study might thus reflect their altered expression seen in embryos exposed to $0.1 \mu \mathrm{M}$ (Saili et al., 2013). 
TABLE 3 | Enriched KEGG pathways for genes containing differentially methylated cytosines.

\begin{tabular}{|c|c|c|c|c|c|}
\hline KEGG pathway & Count & $\%$ & $P$-value & Fold enrichment & Benjamini \\
\hline Dre04070: Phosphatidylinositol signaling system & 46 & 1.083372586 & $5.78 \mathrm{E}-07$ & 2.045716063 & 8.78E-05 \\
\hline Dre04370: VEGF signaling pathway & 32 & 0.753650495 & 3.02E-04 & 1.868899326 & 0.022686307 \\
\hline Dre04010: MAPK signaling pathway & 89 & 2.096090438 & $9.44 \mathrm{E}-04$ & 1.365264965 & 0.046711852 \\
\hline Dre00562: Inositol phosphate metabolism & 30 & 0.706547339 & 0.001297272 & 1.773460107 & 0.048131455 \\
\hline
\end{tabular}

A possible link between behavior and development of the central nervous system is also indicated by the DM genes. Intriguingly, the genes with the most DM sites in this study were all protocadherin 2 gamma subfamily genes. Protocadherins, the largest subgroup within the cadherin superfamily, are transmembrane cell-cell adhesion molecules (Chen and Maniatis, 2013). By regulating cell contact formation and stability, cadherins play a crucial role in tissue morphogenesis and homeostasis. Protocadherins are thought to play roles in axon targeting, synaptic development and neuronal survival (El Hajj et al., 2017), although their specific cellular roles in fish remain poorly defined (Biswas et al., 2012). Hypermethylation of protocadherin genes has been shown to result in transcriptional silencing (Waha et al., 2005; Kawaguchi et al., 2008) and of particular significance, methylation of $p c d h$ promoters by dnmt3b during embryonic stages in mice was demonstrated to modulate the expression of $p c d h$ isoforms, affecting neuron development (Toyoda et al., 2014). A possible link between behavior and protocadherin genes has been shown in rats, where the chromosomal region containing the protocadherin- $\alpha,-\beta$, and $-\gamma$ gene families implicated in synaptogenesis showed the highest differential response to maternal care (McGowan et al., 2011). In humans, the protocadherin gamma gene cluster includes 22 genes divided into three subfamilies (The GeneCards Database, 2018). BPA-induced differential methylation of protocadherin genes has previously been reported in humans (Lam et al., 2011; Faulk et al., 2015), and interactions between BPA and protocadherins are frequently reported (Ali et al., 2014; Calhoun et al., 2014; Tait et al., 2015). Differential methylation of protocadherin 2 gamma genes, which are predominantly expressed in the developing nervous system (Sano et al., 1993), might impact neurons, and the behavioral implications in the evolving embryos should be investigated further.

Another possible link between methylation, gene expression and locomotor behavior may be associated with hormone receptor genes involved in sexual maturation. Genes such as ar, pgrmc1 and esr $2 a$ showed both a reduction in expression at higher BPA concentrations and also contained DM sites, with significantly both pgrmcl and esr $2 a$ containing DM sites within promoter regions. In addition, esr1 showed lower expression and multiple estrogen-related receptor genes contained multiple DM sites. BPA has been demonstrated to both modify methylation and gene expression in estrogen receptor genes and subsequently retard embryo development and maturation of oocytes (Chao et al., 2012; Santangeli et al., 2016).

Global methylation patterns generally followed those observed in other studies. CpG sites are typically highly methylated in vertebrates, around $80 \%$, which correlates with the $81.7 \%$
CpG methylation rate detected in this study (Keller et al., 2016). Conversely, CpG islands (CpGi) tend to be mostly unmethylated and are also relatively sparse in the zebrafish genome, for example CpGi were found to be 11-fold greater in stickleback (Gasterosteus aculeatus) and tetraodon (Tetraodon nigroviridis) than in zebrafish (Han and Zhao, 2008) which may explain why we detected only a small number of DM sites in CpGi regions.

Methylation of promoters can directly regulate gene expression (Farthing et al., 2008; Garcia-Cardona et al., 2014), thereby researchers tend to focus on this, utilizing methods such as targeted SNP arrays or RRBS (Busche et al., 2015). However, these targeted approaches typically ignore methylation in other genomic regions, including gene bodies, where methylation has been shown to also moderate expression via interactions between splice junction and other genomic features (Keller et al., 2016; Yong et al., 2016). Indeed, methylation in gene bodies has been shown to be correlated, and a better indicator of gene expression than promoter methylation in WGBS experiments (Lou et al., 2014). Despite the demonstrated correlation between gene body methylation and expression, the precise function remains unknown, though evidence for direct causal relationships has been found (Yang et al., 2014). Unlike RRBS, which is enriched for promoters and associated CpGi regions, WGBS covers the whole genome and is more reflective of true global methylation patterns, including global CpGi methylation (Dolzhenko and Smith, 2014). We found very high levels of differential methylation in gene bodies (13,739 DM sites in 4,873 genes) which include genes and enriched metabolic pathways that are biologically relevant to BPA exposure. Hypomethylation dominated only in the $5^{\prime}$ untranslated regions and splice junctions, whereas hypermethylation was the predominant response in coding regions, introns, $\mathrm{CpG}$ island flanks, promoter regions and $3^{\prime}$ UTRs. Further research, covering the whole genome and using methods such as WGBS, is needed to elucidate the implication of contaminant-induced differential methylation of non-promoter genomic regions.

According to the DM genes, four pathways previously linked to BPA exposure were significantly affected by the treatment in zebrafish embryos: Phosphatidylinositol signaling system, VEGF signaling pathway, MAPK signaling pathway and Inositol phosphate metabolism. The phosphatidylinositol (PI) signaling system was the most significantly affected pathway, based on a gene group that included calmodulin (calm), CDP-diacylglycerol $(c d)$, diacylglycerol kinase $(d g k)$, inositol kinases, myotubularin ( $m t m)$, PI kinases ( $p i p)$, phosphoinositide kinases (pik), phospholipase C (plc), and protein kinase C (prk). 
In mice adipose cells, BPA has been shown to act via the PI 3-kinase (PIK3) and AKT kinase pathway, resulting in increased triglyceride accumulation and expression of adipocyte genes (Masuno et al., 2005). Two PIK3 regulatory and catalytic subunit genes, $p i k 3 c 3$ and $p i k 3 r 5$, were DM in this study. PIK3 plays a key role in the insulin signaling pathway, but this pathway was not significantly affected in this study (although many DM genes were found in this pathway). VEGF and MAPK signaling pathways were also predicted to be affected by BPA treatment, based on DM genes, with some overlap between the pathways. The VEGF signaling pathway was predicted to be activated based on differential methylation of genes such as mitogen-activated protein kinases (mapk), pip, phosphoinositide-3-kinase (pi3k), protein kinase C (prkc). These genes are also found in phosphatidylinositol signaling system pathway, in addition to protein phosphatase 3 (ppp3) and v-akt murine thymoma viral oncogene homologs (akt3). Previous mammalian studies have demonstrated that BPA affects mRNA and protein expression of VEGF (Buteau-Lozano et al., 2008; Grasselli et al., 2010; Andersson and Brittebo, 2012; Ptak and Gregoraszczuk, 2015), providing a possible link to altered VEGF signaling by BPA in zebrafish embryos. Based on genes where we found multiple DM sites, several within promoters; such as arrestin (arr), calcium channel, voltage-dependent subunits (cacna), fibroblast growth factor ( $f g f)$, mapk's, nuclear factor of activated T-cells ( $n f a t c$ ), platelet derived growth factor receptors $(p g d f b)$, protein kinase C, protein phosphatase 3 subunits ( $p p p 3)$, RAP1A, member of RAS oncogene family, RAS related proteins, ribosomal protein S6 kinase, TAO kinase, transforming growth factor beta receptor, v-akt murine thymoma viral oncogenes; the MAPK signaling pathway was predicted to be affected. Increased phosphorylation of MAPK1 protein is one of the main effects of BPA in animals, a mechanism also demonstrated in zebrafish (Fitzgerald et al., 2015). BPA has also been shown to affect the expression of mapk1 in fish (Villeneuve et al., 2012). Lastly, inositol phosphate metabolism was predicted to be affected based on differential methylation of genes such as inositol polyphosphate-5-phosphatases (inpp5), inositol-tetrakisphosphate 1-kinases (itpk), myotubularin ( $\mathrm{mtm}$ ), phosphatidylinositol kinases and phospholipase C $(p l c)$. As for the other KEGG pathways, a link between BPA exposure and effects on inositol phosphate metabolism has previously been shown in rats (Fernandez et al., 2009). To link the KEGG pathways that have a predicted impact based on differential methylation to altered mRNA expression of the mentioned genes, RNA-seq and WGBS should be performed on the same samples. In this study, the AllPrep DNA/RNA Mini Kit used to isolate DNA failed to produce high-quality RNA which was planned to be used simultaneously for RNA-seq analysis within the current study. However, all four significant KEGG pathways have been linked to the development and function of the nervous system, providing a possible link to the observed behavioral responses. The development of the central nervous system is under tight regulation of numerous signal transduction pathways. For example, the PI, VEGF and MAPK signaling pathways contribute to the regulation of $\mathrm{Ca}^{2+}$ in nervous tissue (Fukunaga and Miyamoto, 1998;
Lo Vasco, 2012; Mackenzie and Ruhrberg, 2012), offering a potential link the behavioral impacts of BPA in developing embryos. Supplementary Table S4 shows nervous system and developmental diseases and functions affected by BPA exposure in the embryos based on genes with significantly DM promoters or sites. Not only genes with DM promoters, but also genes with DM sites often tend to show a negative correlation with differentially expressed genes (DEGs) (Zhang et al., 2017).

The rates of survival, hatch and deformities demonstrate that the levels of BPA in combination with the exposure period applied in this trial were below those that induced whole organism phenotypic symptoms of toxicity, with the exception of the small increase in pericardial edema observed at the highest BPA $(30 \mu \mathrm{M})$ concentration. These results are largely in line with previous findings. For example, pericardial and yolk sac edema were identified in embryonic zebrafish at 24 or $120 \mathrm{hpf}$ after exposure to $>30 \mu \mathrm{M}$ BPA from 8 hpf (Saili et al., 2012, 2013). More recent studies have documented changes to pericardial length at lower BPA concentrations (Kinch et al., 2016).

The behavioral responses of larvae to BPA demonstrate that (A) early developmental exposure of BPA can affect larval locomotor activity, (B) light conditions are a factor in response to BPA exposure, (C) BPA can induce hyper or hypoactivity depending on concentration, light conditions and larval age, and (D) over large concentration differences in exposure, BPA appears to induce non-linear responses in locomotor activity. In this trial, there was over five magnitudes of order difference between the lowest $(0.0001 \mu \mathrm{M})$ and highest $(30 \mu \mathrm{M})$ BPA exposures. Over these concentration ranges hyperactivity was demonstrated with exposure to $0.001 \mu \mathrm{M}$ BPA in comparison to embryos exposed to lower or in other instances, higher, BPA concentrations. Kinch et al. (2015) found that exposure to $0.1 \mu \mathrm{M}$ BPA during different neurogenic periods (16-24 hpf) or (24-36 hpf), but not a pre-neurogenic period (10-16 hpf), resulted in increased locomotor activity at day 5. They showed that BPA induced hyperactivity in embryonic zebrafish at a very low concentration $(0.0068 \mu \mathrm{M})$, but failed to induce a response at $1.0 \mu \mathrm{M}$. In line with our result, these findings demonstrate the non-linear effect of BPA on locomotor activity in embryonic zebrafish. Similarly, embryonic hyperactivity at 5 dpf was observed after neurodevelopmental BPA exposure to $0.01-0.1 \mu \mathrm{M}$ but not higher $(>0.1 \mu \mathrm{M})$ or lower $(<0.01 \mu \mathrm{M})$ BPA concentrations (Saili et al., 2012). Non-linear concentration response patterns are often seen in animals exposed to BPA (Vandenberg, 2014). In adult zebrafish, BPA exposure has been shown to affect swimming at $20 \mu \mathrm{g} / \mathrm{L}$ BPA $(0.087 \mu \mathrm{M})$, and learning at $\geq 0.1 \mu \mathrm{M}$ BPA (Saili et al., 2012; Little and Seebacher, 2015). It thus appears BPA can affect behavioral endpoints in both embryonic and adult zebrafish at very low concentrations.

Based on the behavioral responses and distinct pattern of down-regulation of casp $3 a$, esr $2 a, d n m t 1$ and $c b s$ at $0.01 \mu \mathrm{M} \mathrm{BPA,}$ an exposure concentration of $10 \mu \mathrm{M}$ BPA was selected for the 24-96 hpf DNA methylation exposure study. The most sensitive of the selected gene markers, fos, was down-regulated at 0.001 $\mu \mathrm{M}$ BPA $(0.2 \mu \mathrm{g} / \mathrm{L})$, the lowest concentrations that also induced hyperactivity. Of the genes examined with RT-qPCR, dnmt3aa, $d n m t 3 b$, pgrmc1, esr $2 a$ and mapk1 had a significantly different 
number of DM sites and all except $d n m t 3 b$ and mapk 1 contained $\mathrm{DM}$ sites within promoter regions. Of these, only esr $2 a$ and $d n m t 3 b$ responded significantly to BPA exposure according to the transcriptional analyses. Except for esr $2 a$, there was therefore no strong linkage between the expression and the number of DM sites or promoters of these well-known markers of BPA exposure. With hyperactivity observed at $0.001 \mu \mathrm{M}$ BPA, and significantly altered expression of some of the selected genes from 0.001 to $0.01 \mu \mathrm{M}$ BPA, a lower exposure concentration for the DNA methylation exposure experiment might have provided a stronger link between the studied endpoints.

Although significant only for esr $2 a$ and $a r$, BPA at $0.01 \mu \mathrm{M}$ or higher concentrations appears to down-regulate genes related to sex hormone metabolism. Up-regulation of estrogen-related genes is one of the best-documented effects of endocrine disrupting chemicals such as BPA in fish (Santos et al., 2014; Sun et al., 2014; Zhang et al., 2014; Mathieu-Denoncourt et al., 2015; Qiu et al., 2016). In line with this, an upstream regulator analysis included in the IPA core analysis, comparing the genes with DM promoters (with IPA mapping 1,426 out of a total of 1,866 genes), predicted beta-estradiol, followed by MYCN and LIMS, as the top upstream regulator based on 81 target molecules (Supplementary Table S5). Beta estradiol (followed by ESR1 and topotecan) was also the top predicted upstream regulator using all genes with DM sites, based on 294 target molecules (IPA mapped 10,821 out of 13,929 DM site genes) (Supplementary Table S5). Of other estrogen-related genes examined in this study, vtg1 was not significantly affected by BPA exposure (Figure 5G), however, its response pattern resembled those of esr 1 and esr $2 a$. In various fish species, BPA-induced vtg1 expression has been observed at concentrations below $53 \mu \mathrm{M}$ (Vandenberg et al., 2013). This study thus further demonstrates BPA-induced dysregulation of the sex hormone steroid axis in zebrafish.

In line with earlier zebrafish studies (Calhoun et al., 2014; Chen et al., 2015; Laing et al., 2016), BPA at $>0.01 \mu \mathrm{M}$ exposure down-regulated dnmt1. Reduced dnmt1 transcription was, however, not associated with reduced global DNA methylation in the current study. There was a slight trend toward reduced global DNA methylation (9.0\% for BPA treated vs. 9.2\% global methylation in control group, $p=0.1$ ) in embryos exposed to $10 \mu \mathrm{M}$ BPA for $72 \mathrm{~h}$. In line with our result, Bouwmeester et al. (2016) examined global DNA methylation in zebrafish embryos exposed to 4.9-27.7 $\mu \mathrm{M}$ BPA for various lengths and observed no effects. Other chemicals also failed to induce changes at the global DNA methylation level. The authors speculated that absence of effects on the global scale might indicate that responses are too small in whole-embryos, even with numerous sitespecific methylation modifications (Bouwmeester et al., 2016). These findings suggest that DNA modifications at the global scale might not be a sensitive marker of epigenotoxicity in fish whole-embryo samples.

\section{CONCLUSION}

Significant effects on transcriptional endpoints were seen in zebrafish embryos exposed to $>0.001 \mu \mathrm{M}$ BPA $2-26 \mathrm{hpf}$, and in behavioral endpoints in embryos exposed to 1-30 $\mu \mathrm{M}$ BPA 24-96 hpf. In embryos exposed to $10 \mu \mathrm{M}$ between 24 and $96 \mathrm{hpf}$, promoter regions showed higher hypomethylation than hypermethylation. Most DM genes, however, occurred in gene bodies and these were hypermethylated. The study further identified protocadherin 2 gamma subfamily genes, plus apaf1, asic2, ift172, plxna4, and $r f x 4$, as potential candidates linking DNA methylation and behavioral endpoints in developing fish larvae. According to the DM genes, phosphatidylinositol-, VEGF-, and MAPK signaling pathways and inositol phosphate metabolism were significantly affected by the treatment in zebrafish embryos.

\section{AUTHOR CONTRIBUTIONS}

PO conceived the project, with all co-authors providing advise at various stages of the project, analyzed the transcriptional data, and interpreted all data. PO, SP, and SE designed the experiments, while SP, KS, and SE conducted the experiments. SP analyzed and interpreted the behavioral data. PW developed the WGBS bioinformatics pipeline and analyzed the DNA methylation data. PO, SP, and PW wrote the manuscript and KS, MA, and SE edited the manuscript. All authors read and approved the final manuscript.

\section{FUNDING}

This project was funded by the Norwegian Research Council (EpiSip project 228877).

\section{ACKNOWLEDGMENTS}

The authors want to thank Liv Søfteland, Hui-shan Tung, Synnøve Wintertun, and Øyvind Reinshol (IMR) for technical help.

\section{SUPPLEMENTARY MATERIAL}

The Supplementary Material for this article can be found online at: https://www.frontiersin.org/articles/10.3389/fgene. 2019.00184/full\#supplementary-material

TABLE S1 | Annotated table of DM sites found, including genomic features DM sites fell within, methylation difference (\%), gene annotation (Ensembl gene ID, Entrez gene ID, gene symbol and description), genomic coordinates (chromosome, start, end, strand) and p/q significance values.

TABLE S2 | DM genes for each significant KEGG pathway.

TABLE S3 | DM sites within promoter regions.

TABLE S4 | IPA predicted top upstream regulators based on genes with DM sites.

TABLE S5 | IPA predicted top upstream regulators based on genes with DM promoters. 


\section{REFERENCES}

Akalin, A., Franke, V., Vlahovicek, K., Mason, C. E., and Schubeler, D. (2015). genomation: a toolkit to summarize, annotate and visualize genomic intervals. Bioinformatics 31, 1127-1129. doi: 10.1093/bioinformatics/ btu775

Akalin, A., Kormaksson, M., Li, S., Garrett-Bakelman, F. E., Figueroa, M. E., Melnick, A., et al. (2012). methylKit: a comprehensive R package for the analysis of genome-wide DNA methylation profiles. Genome Biol. 13:R87. doi: 10.1186/ gb-2012-13-10-r87

Ali, S., Steinmetz, G., Montillet, G., Perrard, M. H., Loundou, A., Durand, P., et al. (2014). Exposure to low-dose bisphenol A impairs meiosis in the rat seminiferous tubule culture model: a physiotoxicogenomic approach. PLoS One 9:e106245. doi: 10.1371/journal.pone.0106245

Andersson, H., and Brittebo, E. (2012). Proangiogenic effects of environmentally relevant levels of bisphenol A in human primary endothelial cells. Arch. Toxicol. 86, 465-474. doi: 10.1007/s00204-011-0766-2

Andrews, S. (2016). FastQC A Quality Control Tool for High Throughput Sequence Data. Cambridge: Babraham Institute.

Aniagu, S. O., Williams, T. D., Allen, Y., Katsiadaki, I., and Chipman, J. K. (2008). Global genomic methylation levels in the liver and gonads of the three-spine stickleback (Gasterosteus aculeatus) after exposure to hexabromocyclododecane and 17-beta oestradiol. Environ. Int. 34, 310-317. doi: 10.1016/j.envint.2007. 03.009

Berntssen, M. H. G., Julshamn, K., and Lundebye, A. K. (2010). Chemical contaminants in aquafeeds and Atlantic salmon (Salmo salar) following the use of traditional- versus alternative feed ingredients. Chemosphere 78, 637-646. doi: 10.1016/j.chemosphere.2009.12.021

Berntssen, M. H. G., Maage, A., Julshamn, K., Oeye, B. E., and Lundebye, A. K. (2011). Carry-over of dietary organochlorine pesticides, PCDD/Fs, PCBs, and brominated flame retardants to Atlantic salmon (Salmo salar L.) fillets. Chemosphere 83, 95-103. doi: 10.1016/j.chemosphere.2011.01.017

Biswas, S., Emond, M. R., and Jontes, J. D. (2012). The clustered protocadherins pcdh alpha and pcdh gamma form a heteromeric complex in zebrafish. Neuroscience 219, 280-289. doi: 10.1016/j.neuroscience.2012.05.058

Bonefeld-Jorgensen, E. C., Long, M. H., Hofmeister, M. V., and Vinggaard, A. M. (2007). Endocrine-disrupting potential of bisphenol A, bisphenol A dimethacrylate, 4-n-nonylphenol, and 4-n-octylphenol in vitro: new data and a brief review. Environ. Health Perspect. 115, 69-76. doi: 10.1289/ehp.9368

Bouwmeester, M. C., Ruiter, S., Lommelaars, T., Sippel, J., Hodemaekers, H. M., van den Brandhof, E. J., et al. (2016). Zebrafish embryos as a screen for DNA methylation modifications after compound exposure. Toxicol. Appl. Pharmacol. 291, 84-96. doi: 10.1016/j.taap.2015.12.012

Bugel, S. M., Bonventre, J. A., and Tanguay, R. L. (2016). Comparative developmental toxicity of flavonoids using an integrative zebrafish system. Toxicol. Sci. 154, 55-68. doi: 10.1093/toxsci/kfw139

Burgess, H. A., and Granato, M. (2007). Modulation of locomotor activity in larval zebrafish during light adaptation. J. Exp. Biol. 210, 2526-2539. doi: 10.1242/jeb. 003939

Busche, S., Shao, X. J., Caron, M., Kwan, T., Allum, F., Cheung, W. A., et al. (2015). Population whole-genome bisulfite sequencing across two tissues highlights the environment as the principal source of human methylome variation. Genome Biol. 16:290. doi: 10.1186/s13059-015-0856-1

Buteau-Lozano, H., Velasco, G., Cristofari, M., Balaguer, P., and PerrotApplanat, M. (2008). Xenoestrogens modulate vascular endothelial growth factor secretion in breast cancer cells through an estrogen receptordependent mechanism. J. Endocrinol. 196, 399-412. doi: 10.1677/JOE-070198

Calhoun, K. C., Padilla-Banks, E., Jefferson, W. N., Liu, L., Gerrish, K. E., Young, S. L., et al. (2014). Bisphenol A exposure alters developmental gene expression in the fetal rhesus macaque uterus. PLoS One 9:e85894. doi: 10.1371/journal. pone.0085894

Chao, H. H., Zhang, X. F., Chen, B., Pan, B., Zhang, L. J., Li, L., et al. (2012). Bisphenol A exposure modifies methylation of imprinted genes in mouse oocytes via the estrogen receptor signaling pathway. Histochem. Cell Biol. 137, 249-259. doi: 10.1007/s00418-011-0894-z

Chen, J. F., Sailim, K. S., Lium, Y. Q., Lim, L. L., Zhaom, Y. X., Jia, Y. H., et al. (2017). Developmental bisphenol A exposure impairs sperm function and reproduction in zebrafish. Chemosphere 169, 262-270. doi: 10.1016/j. chemosphere.2016.11.089

Chen, J. F., Xiao, Y. Y., Gai, Z. X., Li, R., Zhu, Z. X., Bai, C. L., et al. (2015). Reproductive toxicity of low level bisphenol A exposures in a two-generation zebrafish assay: evidence of male-specific effects. Aquat. Toxicol. 169, 204-214. doi: 10.1016/j.aquatox.2015.10.020

Chen, W. V., and Maniatis, T. (2013). Clustered protocadherins. Development 140, 3297-3302. doi: 10.1242/dev.090621

Cole, M., Lindeque, P., Halsband, C., and Galloway, T. S. (2011). Microplastics as contaminants in the marine environment: a review. Mar. Poll. Bull. 62, 2588-2597. doi: 10.1016/j.marpolbul.2011.09.025

Dolzhenko, E., and Smith, A. D. (2014). Using beta-binomial regression for high-precision differential methylation analysis in multifactor whole-genome bisulfite sequencing experiments. BMC Bioinformatics 15:215. doi: 10.1186/ 1471-2105-15-215

Durinck, S., Spellman, P. T., Birney, E., and Huber, W. (2009). Mapping identifiers for the integration of genomic datasets with the R/Bioconductor package biomaRt. Nat. Protoc. 4, 1184-1191. doi: 10.1038/nprot.2009.97

El Hajj, N., Dittrich, M., and Haaf, T. (2017). Epigenetic dysregulation of protocadherins in human disease. Semin. Cell Dev. Biol. 69, 172-182. doi: 10. 1016/j.semcdb.2017.07.007

Farthing, C. R., Ficz, G., Ng, R. K., Chan, C. F., Andrews, S., Dean, W., et al. (2008). Global mapping of DNA methylation in mouse promoters reveals epigenetic reprogramming of pluripotency genes. PLoS Genet. 4:e1000116. doi: 10.1371/ journal.pgen.1000116

Faulk, C., Kim, J. H., Jones, T. R., McEachinm, R. C., Nahar, M. S., Dolinoy, D. C., et al. (2015). Bisphenol A-associated alterations in genome-wide DNA methylation and gene expression patterns reveal sequence-dependent and nonmonotonic effects in human fetal liver. Environ. Epigenet. 1:dvv006. doi: 10. 1093/eep/dvv006

Feng, S. H., Cokus, S. J., Zhang, X. Y., Chen, P. Y., Bostick, M., Goll, M. G., et al. (2010). Conservation and divergence of methylation patterning in plants and animals. Proc. Natl. Acad. Sci. U.S.A. 107, 8689-8694. doi: 10.1073/pnas. 1002720107

Fernandez, M., Bianchi, M., Lux-Lantos, V., and Libertun, C. (2009). Neonatal exposure to bisphenol A alters reproductive parameters and gonadotropin releasing hormone signaling in female rats. Environ. Health Perspect. 117, 757-762. doi: 10.1289/ehp.0800267

Fitzgerald, A. C., Peyton, C., Dong, J., and Thomas, P. (2015). Bisphenol A and related alkylphenols exert nongenomic estrogenic actions through a $G$ proteincoupled estrogen receptor 1 (Gper)/epidermal growth factor receptor (Egfr) pathway to inhibit meiotic maturation of zebrafish oocytes. Biol. Reprod. 93:135. doi: 10.1095/biolreprod.115.132316

Fortin, A., Cregan, S. P., MacLaurin, J. G., Kushwaha, N., Hickman, E. S., Thompson, C. S., et al. (2001). APAF1 is a key transcriptional target for p53 in the regulation of neuronal cell death. J. Cell Biol. 155, 207-216. doi: 10.1083/ jcb. 200105137

Fukunaga, K., and Miyamoto, E. (1998). Role of MAP kinase in neurons. Mol. Neurobiol. 16, 79-95. doi: 10.1007/BF02740604

Garcia-Cardona, M. C., Huang, F., Garcia-Vivas, J. M., Lopez-Camarillo, C., Navarro, B. E. D., Olivos, E. N., et al. (2014). DNA methylation of leptin and adiponectin promoters in children is reduced by the combined presence of obesity and insulin resistance. Int. J. Obes. 38, 1457-1465. doi: 10.1038/ijo. 2014.30

Grasselli, F., Baratta, L., Baioni, L., Bussolati, S., Ramoni, R., Grolli, S., et al. (2010). Bisphenol A disrupts granulosa cell function. Domest. Anim. Endocrinol. 39, 34-39. doi: 10.1016/j.domaniend.2010.01.004

Han, L., and Zhao, Z. M. (2008). Comparative analysis of CpG islands in four fish genomes. Comp. Funct. Genomics 2008:565631. doi: 10.1155/2008/565631

Huang, D. W., Sherman, B. T., and Lempicki, R. A. (2009). Systematic and integrative analysis of large gene lists using DAVID bioinformatics resources. Nat. Protoc. 4, 44-57. doi: 10.1038/nprot.2008.211

Iida, A., Shimada, A., Shima, A., Takamatsu, N., Hori, H., Takeuchi, K., et al. (2006). Targeted reduction of the DNA methylation level with 5-azacytidine promotes excision of the medaka fish Tol2 transposable element. Genet. Res. 87, 187-193. doi: 10.1017/S0016672306008184

Kawaguchi, M., Toyama, T., Kaneko, R., Hirayama, T., Kawamura, Y., and Yagi, T. (2008). Relationship between DNA methylation states and transcription of 
individual isoforms encoded by the protocadherin-alpha gene cluster. J. Biol. Chem. 283, 12064-12075. doi: 10.1074/jbc.M709648200

Keller, T. E., Han, P., and Yi, S. V. (2016). Evolutionary transition of promoter and gene body DNA methylation across invertebrate-vertebrate boundary. Mol. Biol. Evol. 33, 1019-1028. doi: 10.1093/molbev/msv345

Kinch, C. D., Ibhazehiebo, K., Jeong, J. H., Habibi, H. R., and Kurrasch, D. M. (2015). Low-dose exposure to bisphenol A and replacement bisphenol S induces precocious hypothalamic neurogenesis in embryonic zebrafish. Proc. Natl. Acad. Sci. U.S.A. 112, 1475-1480. doi: 10.1073/pnas.1417731112

Kinch, C. D., Kurrasch, D. M., and Habibi, H. R. (2016). Adverse morphological development in embryonic zebrafish exposed to environmental concentrations of contaminants individually and in mixture. Aquat. Toxicol. 175, 286-298. doi: 10.1016/j.aquatox.2016.03.021

Krueger, F. (2015). Trim Galore!. Available at: http://www.bioinformatics. babraham.ac.uk/projects/trim_galore/

Krueger, F., and Andrews, S. R. (2011). Bismarck: a flexible aligner and methylation caller for Bisulfite-Seq applications. Bioinformatics 27, 1571-1572. doi: 10.1093/ bioinformatics/btr167

Krzywinski, M., Schein, J., Birol, I., Connors, J., Gascoyne, R., Horsman, D., et al. (2009). Circos: an information aesthetic for comparative genomics. Genome Res. 19, 1639-1645. doi: 10.1101/gr.092759.109

Laing, L. V., Viana, J., Dempster, E. L., Trznadel, M., Trunkfield, L. A., Webster, T. M. U., et al. (2016). Bisphenol A causes reproductive toxicity, decreases dnmt1 transcription, and reduces global DNA methylation in breeding zebrafish (Danio rerio). Epigenetics 11, 526-538. doi: 10.1080/15592294.2016. 1182272

Lam, S. H., Hlaing, M. M., Zhang, X., Yan, C., Duan, Z., Zhu, L., et al. (2011). Toxicogenomic and phenotypic analyses of bisphenol-A early-life exposure toxicity in zebrafish. PLoS One 6:e28273. doi: 10.1371/journal.pone.0028273

Lawrence, M., Huber, W., Pages, H., Aboyoun, P., Carlson, M., Gentleman, R., et al. (2013). Software for computing and annotating genomic ranges. PLoS Comput. Biol. 9:e1003118. doi: 10.1371/journal.pcbi.1003118

Li, X., Guo, J. Y., Li, X., Zhou, H. J., Zhang, S. H., Liu, X. D., et al. (2017). Behavioural effect of low-dose BPA on male zebrafish: tuning of male mating competition and female mating preference during courtship process. Chemosphere 169, 40-52. doi: 10.1016/j.chemosphere.2016.11.053

Lindholst, C., Wynne, P. M., Marriott, P., Pedersen, S. N., and Bjerregaard, P. (2003). Metabolism of bisphenol A in zebrafish (Danio rerio) and rainbow trout (Oncorhynchus mykiss) in relation to estrogenic response. Comp. Biochem. Physiol. C Toxicol. Pharmacol. 135, 169-177.

Little, A. G., and Seebacher, F. (2015). Temperature determines toxicity: bisphenol A reduces thermal tolerance in fish. Environ. Poll. 197, 84-89. doi: 10.1016/j. envpol.2014.12.003

Lo Vasco, V. R. (2012). Phosphoinositide pathway and the signal transduction network in neural development. Neurosci. Bull. 28, 789-800. doi: 10.1007/ s12264-012-1283-x

Lou, S., Lee, H. W., Qin, H., Li, J. W., Gao, Z., Liu, X., et al. (2014). Whole-genome bisulfite sequencing of multiple individuals reveals complementary roles of promoter and gene body methylation in transcriptional regulation. Genome Biol. 15:408. doi: 10.1186/s13059-014-0408-0

Mackenzie, F., and Ruhrberg, C. (2012). Diverse roles for VEGF-A in the nervous system. Development 139, 1371-1380. doi: 10.1242/dev.072348

Maradonna, F., Nozzi, V., Valle, L. D., Traversi, I., Gioacchini, G., Benato, F., et al. (2014). A developmental hepatotoxicity study of dietary bisphenol A in Sparus aurata juveniles. Comp. Biochem. Physiol. C Toxicol. Pharmacol. 166, 1-13. doi: 10.1016/j.cbpc.2014.06.004

Masuno, H., Iwanami, J., Kidani, T., Sakayama, K., and Honda, K. (2005). Bisphenol A accelerates terminal differentiation of 3T3-L1 cells into adipocytes through the phosphatidylinositol 3-kinase pathway. Toxicol. Sci. 84, 319-327. doi: $10.1093 /$ toxsci/kfi08

Mathieu-Denoncourt, J., Wallace, S. J., de Solla, S. R., and Langlois, V. S. (2015). Plasticizer endocrine disruption: highlighting developmental and reproductive effects in mammals and non-mammalian aquatic species. Gen. Comp. Endocrinol. 219, 74-88. doi: 10.1016/j.ygcen.2014.11.003

McGowan, P. O., Suderman, M., Sasaki, A., Huang, T. C. T., Hallett, M., Meaney, M. J., et al. (2011). Broad epigenetic signature of maternal care in the brain of adult rats. PLoS One 6:e14739. doi: 10.1371/journal.pone.0014739
Mirbahai, L., Yin, G. L., Bignell, J. P., Li, N., Williams, T. D., and Chipman, J. K. (2011). DNA methylation in liver tumorigenesis in fish from the environment. Epigenetics 6, 1319-1333. doi: 10.4161/epi.6.11.17890

Nacher-Mestre, J., Serrano, R., Portoles, T., Berntssen, M. H. G., PerezSanchez, J., and Hernandez, F. (2014). Screening of pesticides and polycyclic aromatic hydrocarbons in feeds and fish tissues by gas chromatography coupled to high-resolution mass spectrometry using atmospheric pressure chemical ionization. J. Agric. Food Chem. 62, 2165-2174. doi: 10.1021/jf405 $366 n$

Olsvik, P. A., Lie, K. K., Sturve, J., Hasselberg, L., and Andersen, O. K. (2009). Transcriptional effects of nonylphenol, bisphenol A and PBDE-47 in liver of juvenile Atlantic cod (Gadus morhua). Chemosphere 75, 360-367. doi: 10.1016/ j.chemosphere.2008.12.039

Olsvik, P. A., Williams, T. D., Tung, H. S., Mirbahai, L., Sanden, M., Skjaerven, K. H., et al. (2014). Impacts of TCDD and MeHg on DNA methylation in zebrafish (Danio rerio) across two generations. Comp. Biochem. Physiol. C Toxicol. Pharmacol. 165, 17-27. doi: 10.1016/j.cbpc.2014.05.004

Penglase, S., Hamre, K., and Ellingsen, S. (2014). Selenium prevents downregulation of antioxidant selenoprotein genes by methylmercury. Free Radic. Biol. Med. 75, 95-104. doi: 10.1016/j.freeradbiomed.2014.07.019

Price, M. P., Gong, H., Parsons, M. G., Kundert, J. R., Reznikov, L. R., Bernardinelli, L., et al. (2014). Localization and behaviors in null mice suggest that ASIC1 and ASIC2 modulate responses to aversive stimuli. Genes Brain Behav. 13, 179-194. doi: 10.1111/gbb.12108

Ptak, A., and Gregoraszczuk, E. L. (2015). Effects of bisphenol A and 17 betaestradiol on vascular endothelial growth factor A and its receptor expression in the non-cancer and cancer ovarian cell lines. Cell Biol. Toxicol. 31, 187-197. doi: 10.1007/s10565-015-9303-z

Qiu, W. H., Zhao, Y. L., Yang, M., Farajzadeh, M., Pan, C. Y., and Wayne, N. L. (2016). Actions of bisphenol A and bisphenol S on the reproductive neuroendocrine system during early development in zebrafish. Endocrinology 157, 636-647. doi: 10.1210/en.2015-1785

R Core Team (2016). R: A Language and Environment for Statistical Computing. Vienna: R Foundation for Statistical Computing.

Rissone, A., Sangiorgio, L., Monopoli, M., Beltrame, M., Zucchi, I., Bussolino, F., et al. (2010). Characterization of the neuroligin gene family expression and evolution in zebrafish. Dev. Dyn. 239, 688-702. doi: 10.1002/dvdy.22196

Rochester, J. R. (2013). Bisphenol A and human health: a review of the literature. Reprod. Toxicol. 42, 132-155. doi: 10.1016/j.reprotox.2013.08.008

Rubin, B. S. (2011). Bisphenol A: an endocrine disruptor with widespread exposure and multiple effects. J. Steroid Biochem. Mol. Biol. 127, 27-34. doi: 10.1016/j. jsbmb.2011.05.002

Saili, K. S., Corvi, M. M., Weber, D. N., Patel, A. U., Das, S. R., Przybyla, J., et al. (2012). Neurodevelopmental low-dose bisphenol A exposure leads to early life-stage hyperactivity and learning deficits in adult zebrafish. Toxicology 291, 83-92. doi: 10.1016/j.tox.2011.11.001

Saili, K. S., Tilton, S. C., Waters, K. M., and Tanguay, R. L. (2013). Global gene expression analysis reveals pathway differences between teratogenic and nonteratogenic exposure concentrations of bisphenol A and 17 beta-estradiol in embryonic zebrafish. Reprod. Toxicol. 38, 89-101. doi: 10.1016/j.reprotox.2013. 03.009

Sano, K., Tanihara, H., Heimark, R. L., Obata, S., Davidson, M., St John, T., et al. (1993). Protocadherins: a large family of cadherin-related molecules in central nervous system. EMBO J. 12, 2249-2256. doi: 10.1002/j.1460-2075.1993. tb05878.x

Santangeli, S., Maradonna, F., Gioacchini, G., Cobellis, G., Piccinetti, C. C., Dalla Valle, L., et al. (2016). BPA-induced deregulation of epigenetic patterns: effects on female zebrafish reproduction. Sci. Rep. 6:21982. doi: 10.1038/srep21982

Santos, D., Matos, M., and Coimbra, A. M. (2014). Developmental toxicity of endocrine disruptors in early life stages of zebrafish, a genetic and embryogenesis study. Neurotoxicol. Teratol. 46, 18-25. doi: 10.1016/j.ntt.2014. 08.002

Sawyer, S. J., Gerstner, K. A., and Callard, G. V. (2006). Real-time PCR analysis of cytochrome P450 aromatase expression in zebrafish: gene specific tissue distribution, sex differences, developmental programming, and estrogen regulation. Gen. Comp. Endocrinol. 147, 108-117. doi: 10.1016/j.ygcen.2005. 12.010 
Sun, L. W., Lin, X., Jin, R., Peng, T., Peng, Z. H., and Fu, Z. W. (2014). Toxic effects of bisphenol A on early life stages of Japanese medaka (Oryzias latipes). Bull. Environ. Contam. Toxicol. 93, 222-227. doi: 10.1007/s00128-014-1298-2

Tait, S., Tassinari, R., Maranghi, F., and Mantovani, A. (2015). Bisphenol A affects placental layers morphology and angiogenesis during early pregnancy phase in mice. J. Appl. Toxicol. 35, 1278-1291. doi: 10.1002/jat.3176

The GeneCards Database (2018). Available at: http://www.genecards.org

Toyoda, S., Kawaguchi, M., Kobayashi, T., Tarusawa, E., Toyama, T., Okano, M., et al. (2014). Developmental epigenetic modification regulates stochastic expression of clustered protocadherin genes, generating single neuron diversity. Neuron 82, 94-108. doi: 10.1016/j.neuron.2014.02.005

Vandenberg, L. N. (2014). Non-monotonic dose responses in studies of endocrine disrupting chemicals: bisphenol a as a case study. Dose Response 12, 259-276. doi: 10.2203/dose-response.13-020.Vandenberg

Vandenberg, L. N., Ehrlich, S., Belcher, S. M., Ben-Jonathan, N., Dolinoy, D. C., Hugo, E. R., et al. (2013). Low dose effects of Bisphenol A: an integrated review of in vitro, laboratory animal and epidemiology studies. Endocr. Disruptors 1:e25078. doi: 10.4161/endo.26490

Vandesompele, J., De Preter, K., Pattyn, F., Poppe, B., Van Roy, N., De Paepe, A., et al. (2002). Accurate normalization of real-time quantitative RT-PCR data by geometric averaging of multiple internal control genes. Genome Biol. 3:RESEARCH0034. doi: 10.1186/gb-2002-3-7-research0034

Villeneuve, D. L., Garcia-Reyero, N., Escalon, B. L., Jensen, K. M., Cavallin, J. E., Makynen, E. A., et al. (2012). Ecotoxicogenomics to support ecological risk assessment: a case study with bisphenol A in fish. Environ. Sci. Technol. 46, 51-59. doi: 10.1021/es201150a

Waha, A., Guntner, S., Huang, T. H., Yan, P. S., Arslan, B., Pietsch, T., et al. (2005). Epigenetic silencing of the protocadherin family member PCDH-gamma-A11 in astrocytomas. Neoplasia 7, 193-199. doi: 10.1593/neo.04490

Walker, D. M., and Gore, A. C. (2011). Transgenerational neuroendocrine disruption of reproduction. Nat. Rev. Endocrinol. 7, 197-207. doi: 10.1038/ nrendo.2010.215

Wang, X. C., Dong, Q. X., Chen, Y. H., Jiang, H., Xiao, Q., Wang, Y. J., et al. (2013). Bisphenol A affects axonal growth, musculature and motor behavior in developing zebrafish. Aquat. Toxicol. 142, 104-113. doi: 10.1016/j.aquatox. 2013.07.011

Wu, M. H., Xu, H., Shen, Y., Qiu, W. H., and Yang, M. (2011). Oxidative stress in zebrafish embryos induced by short-term exposure to bisphenol a, nonylphenol, and their mixture. Environ. Toxicol. Chem. 30, 2335-2341. doi: 10.1002/ etc. 634

Yang, X., Han, H., De Carvalho, D. D., Lay, F. D., Jones, P. A., and Liang, G. (2014). Gene body methylation can alter gene expression and is a therapeutic target in cancer. Cancer Cell 26, 577-590. doi: 10.1016/j.ccr.2014.07.028

Yates, A., Akanni, W., Amode, M. R., Barrell, D., Billis, K., Carvalho-Silva, D., et al. (2016). Ensembl 2016. Nucleic Acids Res. 44, D710-D716. doi: 10.1093/ nar/gkv1157

Yong, W. S., Hsu, F. M., and Chen, P. Y. (2016). Profiling genomewide DNA methylation. Epigenet. Chromatin 9:26. doi: 10.1186/s13072-0160075-3

Zhang, W., Han, S., and Sun, K. (2017). Combined analysis of gene expression, miRNA expression and DNA methylation profiles of osteosarcoma. Oncol. Rep. 37, 1175-1181. doi: 10.3892/or.2016.5324

Zhang, Y. Y., Gao, J. C., Xu, P., Yuan, C., Qin, F., Liu, S. Z., et al. (2014). Low-dose bisphenol A disrupts gonad development and steroidogenic genes expression in adult female rare minnow Gobiocypris rarus. Chemosphere 112, 435-442. doi: 10.1016/j.chemosphere.2014.04.089

Conflict of Interest Statement: The authors declare that the research was conducted in the absence of any commercial or financial relationships that could be construed as a potential conflict of interest.

Copyright (c) 2019 Olsvik, Whatmore, Penglase, Skjorven, Anglès d'Auriac and Ellingsen. This is an open-access article distributed under the terms of the Creative Commons Attribution License (CC BY). The use, distribution or reproduction in other forums is permitted, provided the original author(s) and the copyright owner(s) are credited and that the original publication in this journal is cited, in accordance with accepted academic practice. No use, distribution or reproduction is permitted which does not comply with these terms. 